\title{
Os Sciaenidae (Teleostei: Perciformes) da Baía de Santos (SP), Brasil
}

\author{
Roberto GIANNINI ${ }^{1}$ \& Alfredo Martins PAIVA FILHO \\ Instituto Oceanográficu da Universidade de São Paulo \\ (Caixa Postal 9075, 01051, São Paulo, SP)
} \begin{abstract}
The purpose of this study was to describe the occurrence and the spatial
partitioning of the most abundant juvenile sciaenid fishes in the Bay of Santos, based upon the variability in the occurrence and abundance and influence of environmental factors. Monthly diurnal beach seine haul and bottom trawl samples were made between March 1985 and May 1986. Twenty species of sciaenid fishes were collected in the region, all occurrying in bottom trawls and nine of them in beach seine hauls. Among them, Stellifer rastrifer, Isopisthus parvipinnis, Paralonchurus brasiliensis, Micropogonias furmieri, Stellifer brasiliensis, Menticirrhus americanus and Menticirrhus littoralis were found year-round and constituted more than $90 \%$ of total catches from the Bay of Santos and adjacent beach region; their coexistence was possible due to seasonal and spatial differences in relative abundance and due to water temperature and salinity influence. $S$. rastrifer occurred mainly in bottom trawls, during winter, in colder waters with medium depth and salinity and in all strata. I. parvipinnis, $P$. brasiliensis and $S$. brasiliensis occurred mainly in bottom trawls, during winter, spring and fall, respectively, in colder, deeper and saltier waters and in outer sirata. M. fumieri and $M$. americanus occurred in bottom trawls and beach seine hauls and, mainly, during summer, in warmer, shallower and with less salinity waters and in inner strata. $M$. littoralis occurred mainly in beach seine hauls, during winter, in colder waters and in all sample stations.
\end{abstract}

- Descriptors: Marine fish, Seasonal distribution, Biomass, Population number, Environmental effects, Sciaenidae, Estuaries, Santos, Sāo Vicente, Brazil.

- Descritores: Peixes marinhos, Distribuição sazonal, Biomassa, Número da população, Efeitos ambientais, Sciaenidae, Estuários, Santos:SP, São Vicente: SP.

\section{Introdução}

No litoral sudeste, os peixes da família Sciaenidae constituem um dos mais importantes recursos da pesca demersal costeira, sendo capturados por barcos arrasteiros, camaroneiros e parelhas. As principais espécies comercializadas representam cerca de 6.000 toneladas anuais desembarcadas no litoral do Estado de São Paulo, valor esse muito inferior ao desembarque real, já que os cienídeos são dominantes nas categorias denominadas "mistura" e "rejeito", oriundas principalmente da pesca do camarāo sete-barbas (Giannini, 1989).

O complexo baía-estuário de Santos e São Vicente, considerado como uma das áreas mais poluídas do litoral

(1) Pós-graduando do Departamento de Oceanografia Biológica. Contr. $n^{e} 717$ do Inst. oceanogr. da Usp. brasileiro em decorrência do forte impacto ambiental a que está submetido, se constitui num dos grandes criadouros naturais de pescado do sudeste do Brasil, apresentando uma alta diversidade e grande abundância de peixes (Paiva Filho et al., 1987).

Embora numerosos trabalhos tenham sido realizados nesse ecossistema, possibilitando um amplo conhecimento de suas características físicas, químicas, geológicas e biológicas, poucos sāo os estudos relacionados com a estrutura da comunidade ictiofaunística (Giannini, 1989).

Do total de peixes capturados durante vários programas de pesquisa na regiāo, com diferentes artes de pesca entre 1979 e 1986, a família Sciaenidae foi dominante nos arrastos de fundo na baía, bem como na região costeira adjacente. Esta família esteve também presente com um grande número de espécies nos arrastos de praia costeiro e estuarino (Paiva Filho et al., 1987).

Descritas para a regiāo de Santos preliminarmente por Vazzoler (1969), a estrutura das populaçōes de 
Sciaenidae e os mecanismos de repartição do habitat na regiāo não são conhecidos até o presente momento.

Considerando-se a importância da família Sciaenidae como recurso pesqueiro e como um dos elementos do ecossistema, este trabalho teve como objetivos determinar quais as espécies de cienídeos que ocorrem na regiāo e analisar a sua coexistência, com base na variação sazonal e espacial da abundância e da influência de fatores ambientais.

\section{Material e métodos}

A área estudada compreendeu a Baía de Santos, desde a barra até sua regiāo mais interna de praias, pertencente ao complexo baía-estuário de Santos e São Vicente (Fig. 1).

A Baía de Santos é a principal comunicação entre o complexo estuarino e a regiāo costeira adjacente, apresentando praias arenosas de baixa declividade margeadas por manguezais (Sousa, 1979; Tommasi, 1979).

A circulação das águas é regida por correntes de maré (SONDOTÉCNICA, 1977) e duas áreas sedimentologicamente distintas são encontradas: a oeste, de maior energia e fundos de areia muito fina e bem selecionada, e a leste, de baixa energia e fundos de silte mal selecionado e detritos vegetais, caracterizando assim dois ambientes ecologicamente distintos, com maior diversidade e abundância da comunidade bentônica no setor leste da baía (Fulfaro \& Ponçano, 1976; Tommasi, 1979).

As amostras utilizadas nesse trabalho foram provenientes de capturas mensais diurnas, entre março de 1985 e maio de 1986. A regiāo estudada foi dividida em 12 áreas para amostras com arrastos de fundo e, em 13 áreas para amostras com arrastos de praia, definindo assim os setores de amostragem A, B, C e PR (Fig. 1).

Dois tipos de arte de pesca foram utilizados:

Arrastos de fundo, em sentido contrário ao da corrente, com velocidade de cerca de 2 nós e tempo de arrasto de 5 minutos (unidade de esforço), com uma rede de portas de $16,7 \mathrm{~m}$ de largura na tralha inferior e malhas de $20 \mathrm{~mm}$ e $15 \mathrm{~mm}$ (n6́ a n6) no corpo e no sacador respectivamente; mensalmente foram amostradas cerca de 8 áreas;

Arrastos de praia, com uma rede de calāo de $15,0 \mathrm{~m}$ de comprimento, $1,5 \mathrm{~m}$ de altura e malha de $5 \mathrm{~mm}$ (n6́ a n6), sendo amostradas mensalmente cerca de 12 áreas, cada arrasto cobrindo uma distância de aproximadamente $150 \mathrm{~m}$ (unidade de esforço).

Parâmetros climatologicos e hidrográficos foram obtidos, visando uma melhor caracterização da região estudada. Dados da temperatura do ar, precipitação e pressão atmosférica foram obtidos junto à Estação Meteorológica da Base Aérea de Santos e expressos como a média sazonal. Os dados hidrográficos (temperatura, salinidade e oxigênio dissolvido) foram obtidos da água de superfície e de fundo e expressos como a média sazonal e a média por setor de coleta (Fig. 2).

Toda a ictiofauna coletada foi fixada em formalina a $10 \%$ e, no laboratório, todos os peixes foram identificados, contados e pesados. Resultados preliminares relativos à ictiofauna total foram apresentados, no intuito de se permitir comparaçōes com as populaçōes de Sciaenidae (Figs 3 e 4).

A análise da estrutura das populaçōes de Sciaenidae foi feita a partir das variaçōes sazonais e espaciais da abundância das espécies, utilizando-se a captura média por unidade de esforço (CPUE) (Figs 3 a 8).

Considerou-se as estaçōes do ano como: OUTONO (março a maio), INVERNO (junho a agosto), PRIMAVERA (setembro a novembro) e VERÄO (dezembro a fevereiro).

Para descrever quantitativamente a relaçāo entre as variaçōes da abundância das espécies de Sciaenidae mais abundantes e associaçōes entre variáveis hidrográficas, temporais e espaciais, foi utilizada análise em componentes principais (Legendre \& Legendre, 1983; Pla, 1986). A matriz de correlação entre as espécies foi calculada a partir do número de exemplares capturados por unidade de esforço (CPUE), após transformaçăo desses valores para $\log (x+1)$, onde $x$ é a CPUE, para cada espécie, por amostra (Fig. 9).

\section{Resultados e discussão}

\section{Condiçōes meteorológicas e hidrográficas}

Durante o inverno, predominaram condiçōes climatológicas estáveis, com altos valores da pressāo atmosférica e baixos valores da temperatura do ar e de precipitação. Como reflexo, observou-se uma homogeneidade dos parâmetros oceanográficos em toda a coluna de água, com baixos valores da temperatura da água, da concentração de oxigênio dissolvido e altos valores da salinidade (Figs 2.1 e 2.2).

Da primavera ao outono, baixos valores da pressão atmosférica ocasionaram instabilidades climatógicas e uma ruptura na homogeneidade das condições oceanográficas. Neste período, registrou-se altos índices de pluviosidade e conseqüentemente, baixos valores da salinidade da água. Observou-se altos valores das temperaturas do ar e da água, variaçōes na concentraçāo de oxigênio dissolvido e a ocorrência de estratificaçōes térmicas e salinas (Figs $2.1 \mathrm{e} \mathrm{2.2)}$.

A formação de termoclina e haloclina no período de verão e a predominância de condições oceanográficas mais homogêneas durante o inverno foram relatadas por Mesquita (1974), para águas costeiras da plataforma da região de Santos.

A temperatura da água mostrou um mesmo padrão sazonal em toda a coluna de água, com menores valores no inverno e maiores no verão-outono, relacionados com a temperatura atmosférica. Os valores foram menores para a água de fundo. Médias das temperaturas das amostras da água de superfície e de fundo variaram menos de $1,0{ }^{\circ} \mathrm{C}$ entre si, no inverno. A maior diferença entre ambas, a partir da primavera, esteve relacionada, possivelmente, à penetração de águas frias de plataforma. A temperatura da água foi ligeiramente superior nas àmostras de praia e superior à temperatura atmosférica. Foi verificada uma pequena variação espacial dos valores da temperatura da água, a qual aumenta no sentido interno da baía, com os maiores valores junto às áreas abrigadas e marginais de praia (Figs 2.2 e 2.3). 

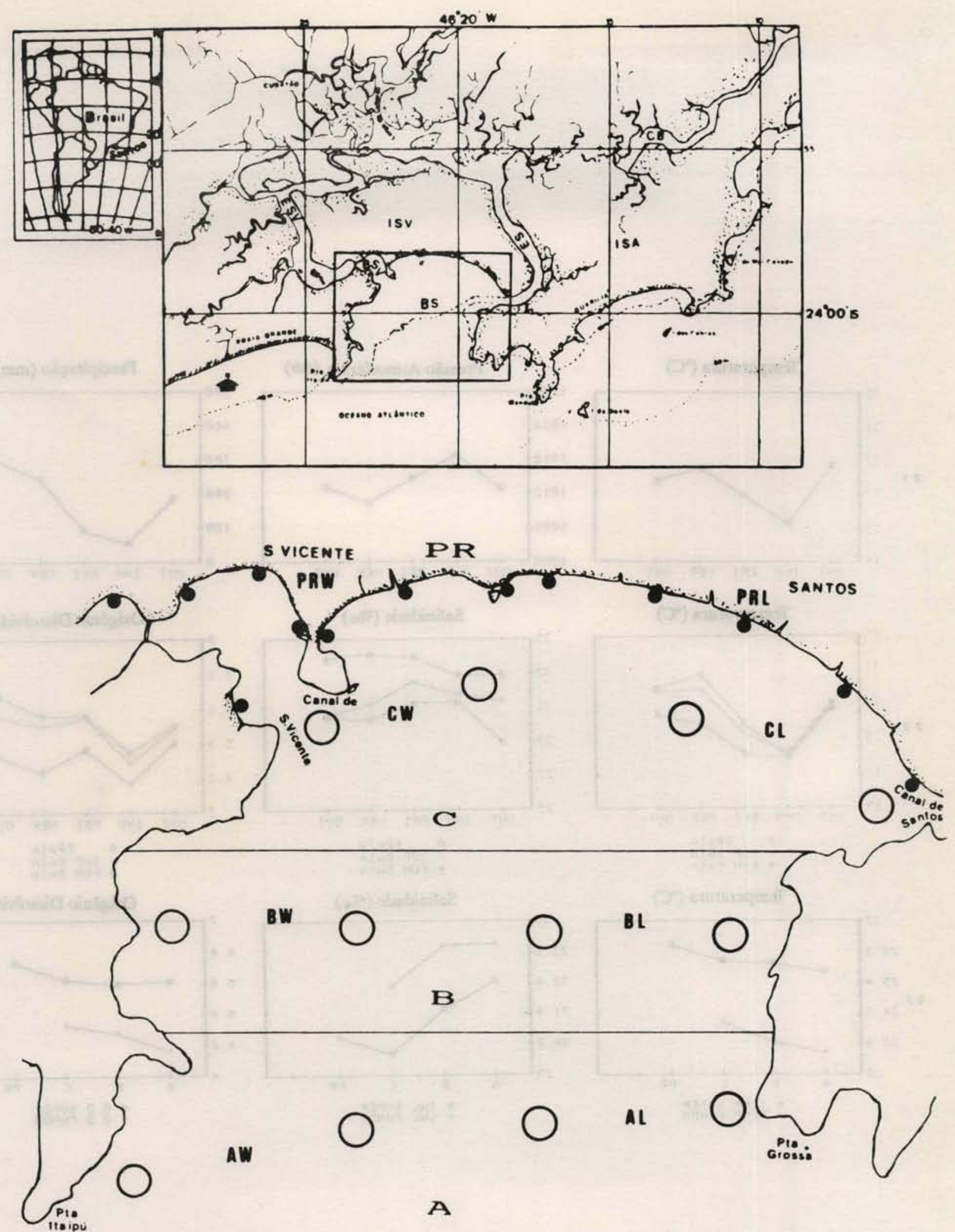

Fig. 1. Mapa da região de Santos e São Vicente, conforme carta da DHN no 1711, com as áreas de coleta assinaladas. As letras A, B, C e PR, correspondem aos setores e as letras AL, AW, BL, BW, CL, CW, PRL, e PRW aos sub-setores de amostragem. ISV (llha de São Vicente); ISA (Illa de Santo Amaro); CB (Canal da Bertioga); ESV (Estuário de São Vicente); ES (Estuário de Santos); BSV (Baía de São Vicente); BS (Baía de Santos).

Arrastos de Fundo (O) Arrastos de Praia (•) 

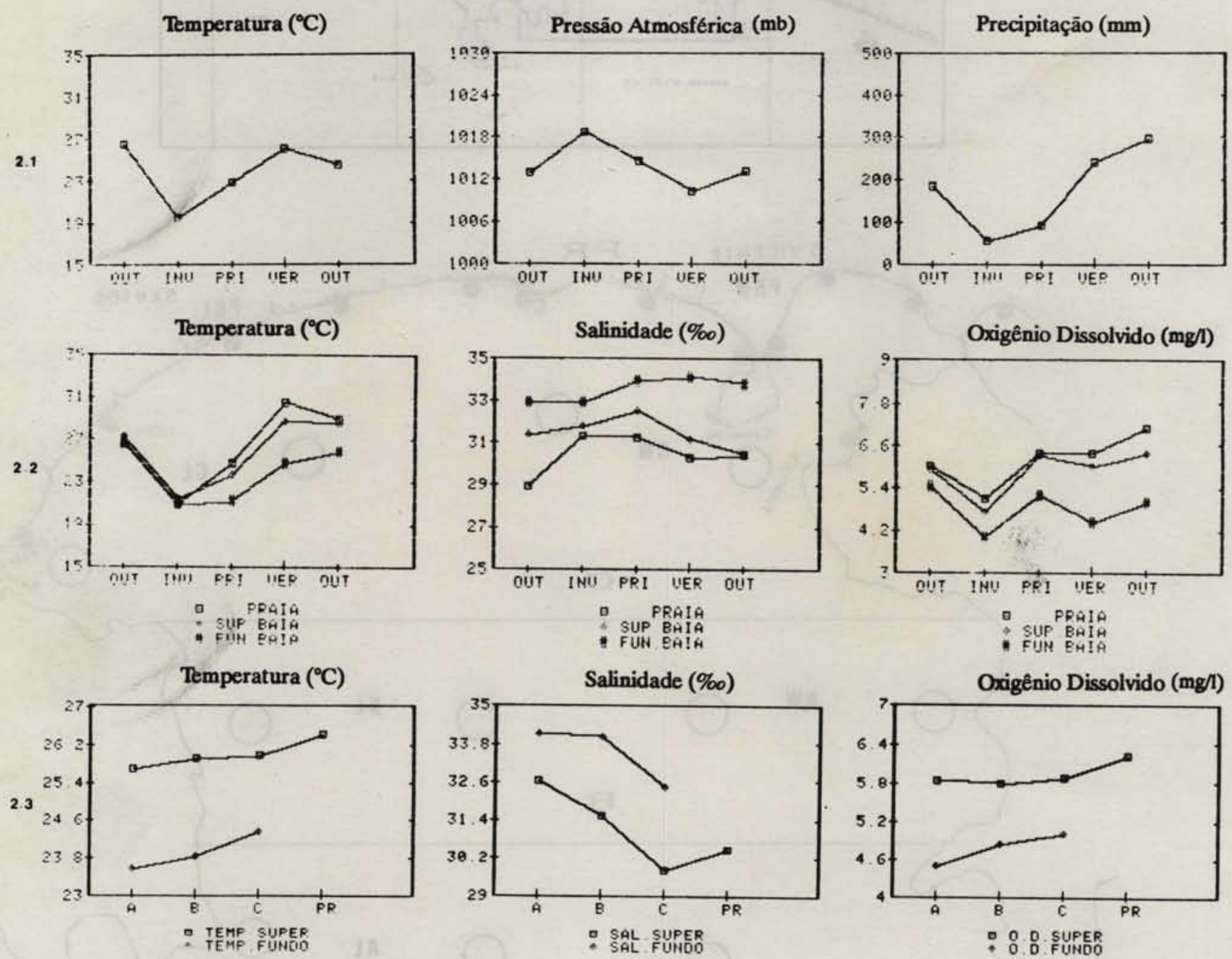

Fig. 2. Valores médios sazonais dos parâmetros climatológicos (2.1) e dos parâmetros hidrográficos sazonais (2.2) e por setor de amostragem (2.3). 
A salinidade não. apresentou grandes variações durante o período de amostragem e na coluna de água. Os valores de salinidade da água de superfície nas amostras da baía e de praia foram menores no verão-outono, relacionados ao intenso período de chuvas na região, e maiores no inverno-primavera. Os menores valores da salinidade foram obtidos nas amostras de praia. A salinidade de fundo se apresentou mais homogênea, com maiores valores médios que a de superfície, principalmente no verão, relacionados, provavelmente, à intrusão de águas frias e salinas da plataforma. A salinidade decresceu em direção à porção mais interna da baía, onde a contribuiçāo de água doce pelos estuários é mais evidente (Figs $2.2 \mathrm{e} 2.3$ ).

Menores valores da salinidade de superfície no veräo, relacionados como intenso período de chuvas nesta estação foram citados por Matsuura (1977).

Concentrações médias de oxigênio dissolvido da água de superfície apresentaram menores valores no inverno, associados às condiçōes oceanográficas homogêneas. Da primavera ao outono, os teores de oxigênio aumentaram, relacionados, possivelmente, com as alteraçōes oceanográficas vigentes e um padrão de circulação de água mais dinâmico. Idêntica variação sazonal dos valores de oxigênio foi observada para as amostras de água de fundo, à excessão do verão, quando os baixos valores observados poderiam ser relacionados à estratificação térmica ocorrida. Os valores foram ligeiramente superiores nas amostras de praia. A concentração de oxigênio dissolvido se manteve constante na água de superfície, com valores um pouco superiores no setor $\mathrm{C}$ e sempre superiores às concentraçōes da água de fundo, a qual apresentou semelhante padrāo espacial, embora mais acentuado(Figs 2.2 e 2.3).

Baixos valores das temperaturas do ar e da água e da precipitação durante o inverno, relacionados inversamente com a salinidade, foram relatados por Tommasi (1979), Cunha (1981), Paiva Filho (1982) e Chao et al. (1985) em ecossistemas costeiros e estuarinos do litoral sudeste-sul do Brasil.

Os valores médios das temperatura, salinidade e concentração de oxigênio dissolvido das águas de superfície e de fundo obtidos neste trabalho, foram muito semelhantes aos encontrados por outros autores na mesma regiāo (Tommasi, 1979; Corbisier, 1981; Pereira, 1985; Paiva Filho \& Toscano, 1987).

A pequena variação da temperatura, salinidade e oxigênio dissolvido na coluna de água e nos setores indicaram que as águas da Baía de Santos foram homogêneas grande parte do ano; Chao et al. (1985) chegaram a semelhante conclusão para as águas estuarinas da Lagoa dos Patos (RS).

As amostras de praia apresentaram maiores valores das temperatura, salinidade e oxigênio, com temperaturas ligeiramente superiores à temperatura do ar. Cunha (1981) e Chao et al. (1985) constataram semelhante padrão em amostras nas praias do Cassino e da Lagoa dos Patos (RS).

\section{Composição ictiofaunística}

Foram efetuados 106 arrastos de fundo e 172 arrastos de praia, capturando-se 118 espécies (47 familias) de peixes estuarinos e marinhos (63.201 peixes; $611.220,4 \mathrm{~g}$ ) (Figs 3 e 4).

Os Arrastos de Fundo capturaram 92 espécies de 35 famílias e com uma média de 13,8 espécies por arrasto. $O$ maior número de espécies ocorreu durante o verāo e outono. Foram capturados 23.869 peixes (CPUE de 225,2) com um peso total de 526.298,0 gramas (CPUE de 4.965,1 g). A abundância, em número e em peso apresentou o mesmo padrāo sazonal, com menores valores no inverno e maiores no outono (Figs 3.1, 3.2 e 3.3).

Do total das 35 famílias coletadas, seis representaram mais de $93,0 \%$ do total capturado em número, sendo a família Sciaenidae a que apresentou maior número de espécies (vinte) e a maior abundância (71,9 \% das capturas) (Fig. 3.4). A dominância de cienídeos em números de espécies e de indivíduos capturados foi relatada para diversas regiōes costeiras do sudeste-sul do Brasil (Vazzoler, 1975; Cunningham, 1983; Nonato et al., 1983; Zani-Teixeira, 1983; Chao et al., 1985; Coelho et al., 1986; Paiva Filho \& Schmiegelow, 1986; Paiva Filho et al., 1987).

Os Arrastos de Praia capturaram 67 espécies (média de 7,3 espécies por arrasto), pertencentes a 31 famflias. Foram coletados 39.332 peixes (CPUE de 228,7) com um peso total de $84.922,4$ gramas (CPUE de $493,7 \mathrm{~g}$ ). A abundância, em número e em peso foi maior no outono, decrescendo a partir deste (Figs 4.1, 4.2 e 4.3).

Do total das 31 famílias coletadas, seis representaram mais de $90,0 \%$ do total capturado, em número. A família Sciaenidae, uma das mais importantes em número de espécies (nove), correspondeu a $10,0 \%$ das capturas (Fig. 4.4). A baixa abundância numérica dos Sciaenidae, ainda que com grande número de espécies representativas, foi relatada por Matsuura \& Nakatani (1979), Cunha (1981), Paiva Filho (1982), Chao et al. (1985), Paiva Filho et al. (1987) e Paiva Filho \& Toscano (1987), para diversas praias costeiras e estuarinas do litoral sudeste-sul do Brasil.

Informaçōes mais detalhadas sobre a composição da ictiofauna da região podem ser obtidas nos trabalhos de Paiva Filho et al. (1987) e Ribeiro Neto (1989).

Estrutura das populações de cienídeos em relaçẩo à abundância

Das vinte espécies de cienídeos, todas ocorreram nos arrastos de fundo, e nove na regiāo de praias (Tab. 1).

Nos Arrastos de Fundo, o padrão de abundância, em número e em peso, foi semelhante ao da captura total, tendo sido coletados 17.169 peixes (CPUE de 162,0) com um peso total de 304.273,4 gramas (CPUE de 2.870,5 g) (Figs 3.2 e 3.3).

Nos Arrastos de Praia, a abundância, em número e em peso, foi praticamente constante ao longo do período de estudo, com um único pico na primavera, sendo capturados 3.935 peixes (CPUE de 22,9) com um peso total de 10.972,5 gramas (CPUE de 63,8g) (Figs $4.2 \mathrm{e} 4.3$ ). 

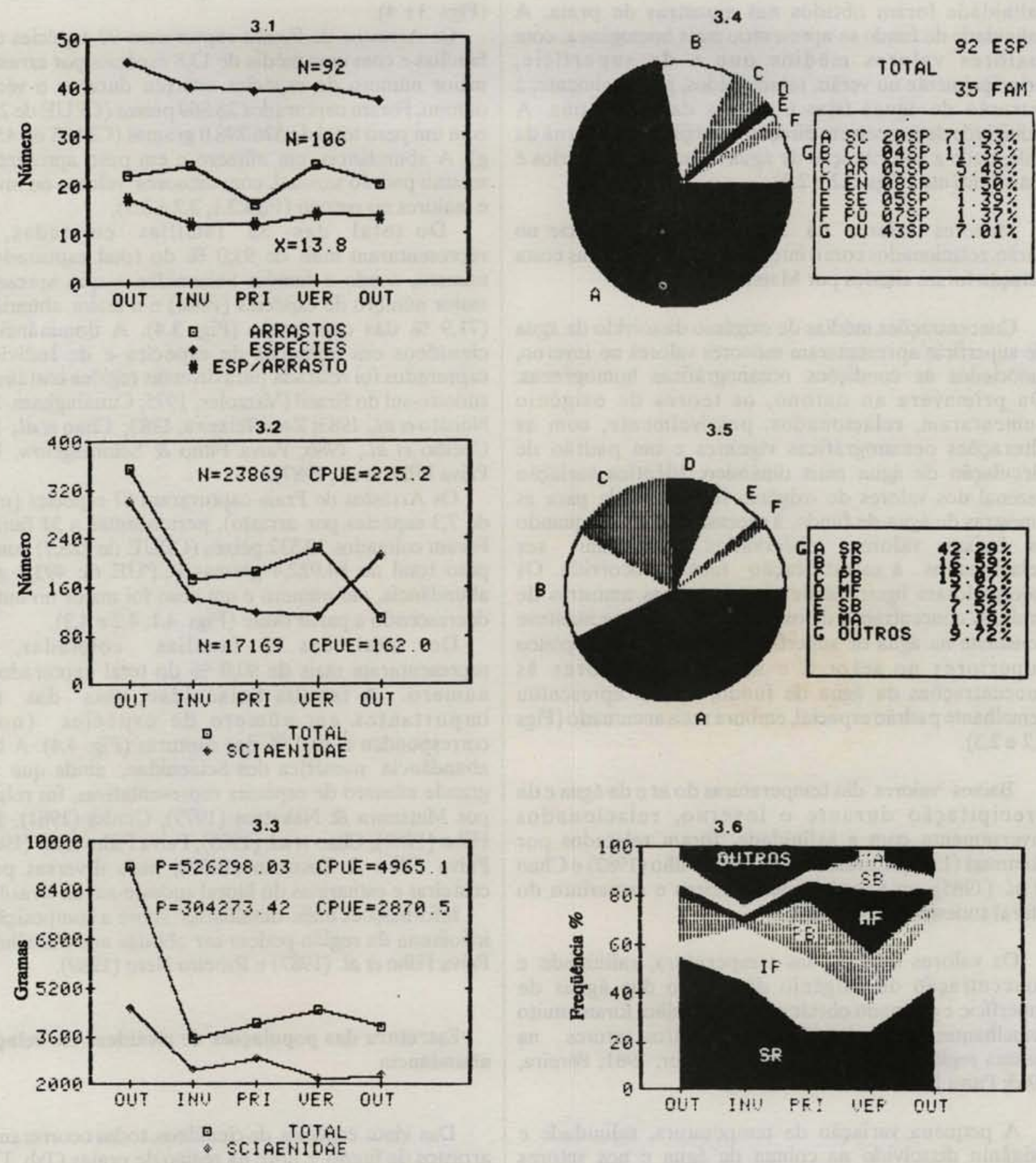

Fig. 3. Médias do número de espécies, de arrastos de pesca ede espécies por arrasto (3.1), das capturas médias dos pelxes (CPUE) em número (3.2) e em peso (3.3), percentuals das principais famflias (3.4) e espécles (3.5) em relação ao número total e freqüêncla acumulada das principals espécies de Sclaenidae (3.6), por estação do ano nos arrastos de fundo. SC, CL, AR, EN, SE e PO representam as famflias Sciaenidae, Clupeidae, Arildae, Engraulldae, Serranidae ePomadasyidae, respectivamente $\theta$ as letras SR, IP, PB, MF, MA e ML representam as espécies principals de Sciaenidae (vide Tab. 1); OUTROS = Demais familas e espécies. 

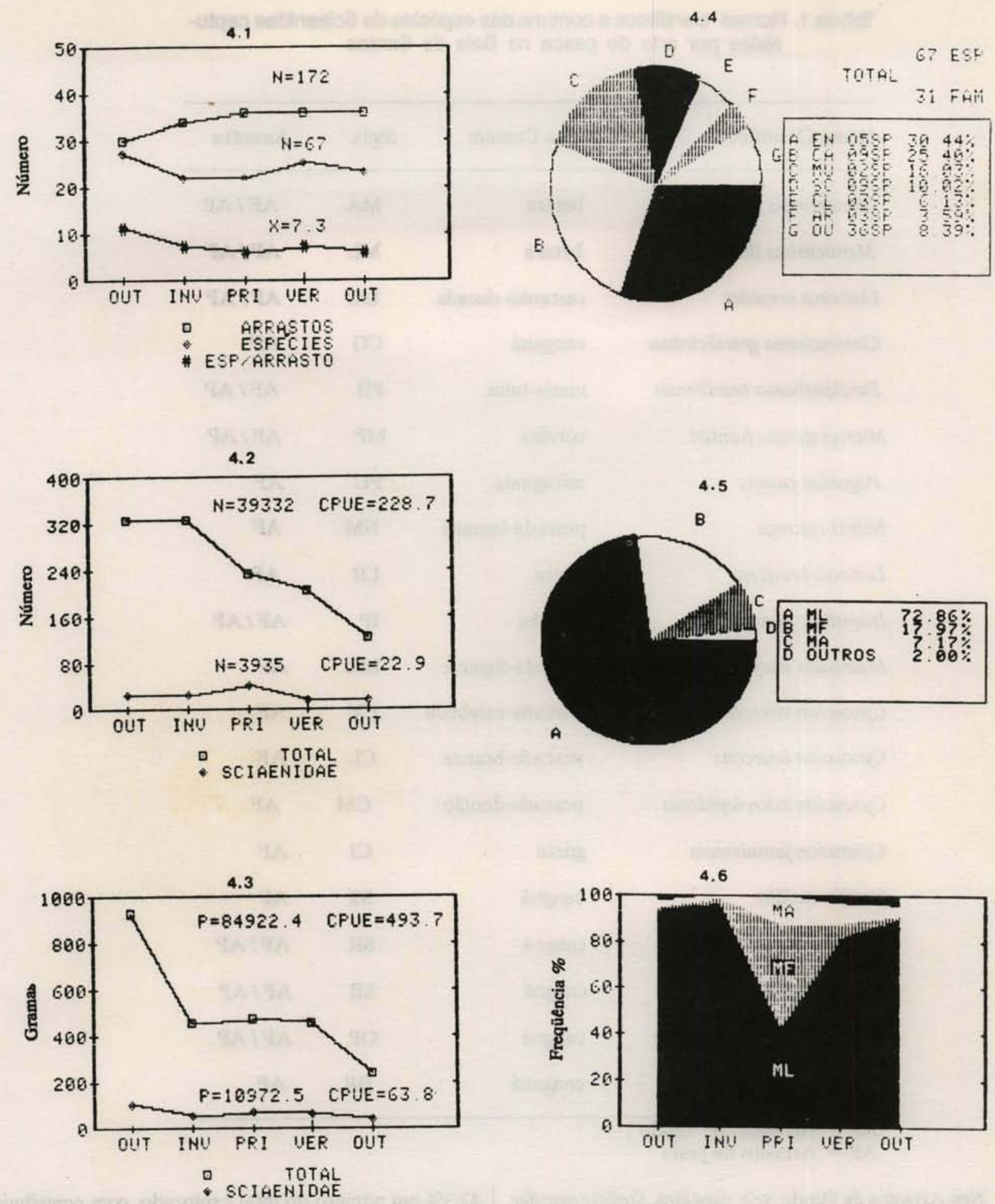

Fig. 4. Médias do número de espécies, de arrastos de pesca ede espécies por arrasto (4.1), das capturas médias dos pelxes (CPUE) em número (4.2) e em peso (4.3), percentuais das principais famnlias (4.4) e espécies (4.5) em relação ao número total e freqüência acumulada das principais espécies de Sciaenidae (4.6), por estação do ano nos arrastos de praia. EN, CA, MU, SC, CL ө AR representam as famflias Engraulidae, Carangidae, Mugilidae, Sciaenidae, Clupeidae e Ariidae, respectivamente $\theta$ as letras ML, MF e MA representam as espécies principais de Sciaenidae (vide Tab. 1); OUTROS = Demais famflias e espécies. 
Tabela 1. Nomes cientfificos e comuns das espécies de Sciaenidae capturadas por arte de pesca na Bala de Santos

\begin{tabular}{|c|c|c|c|}
\hline Nome Cientifico & Nome Comum & Sigla & Amostra \\
\hline Menticirthus americanus & betara & MA & $\mathrm{AF} / \mathrm{AP}$ \\
\hline Menticirrhus littoralis & betara & ML & $\mathbf{A F} / \mathbf{A P}$ \\
\hline Umbrina coroides & castanha-riscada & UC & $\mathbf{A F} / \mathbf{A P}$ \\
\hline Ctenosciaena gracilicirthus & cangauá & CG & $\mathbf{A F}$ \\
\hline Paralonchurus brasiliensis & maria-luísa & PB & $\mathbf{A F} / \mathbf{A P}$ \\
\hline Micropogonias fumieri & corvina & MF & AF/AP \\
\hline Pogonias cromis & miraguaia & PC & AF \\
\hline Nebris microps & pescada-banana & NM & AF \\
\hline Larimus breviceps & oveva & LB & $\mathbf{A F}$ \\
\hline Isopisthus parvipinnis & tortinha & IP & $\mathbf{A F} / \mathbf{A P}$ \\
\hline Macrodon ancylodon & pescada-foguete & MC & AF \\
\hline Cynoscion virescens & pescada-cambucu & CV & AF \\
\hline Cynoscion leiarchus & pescada-branca & CL & AF \\
\hline Cynoscion microlepidotus & pescada-dentāo & CM & AF \\
\hline Cynoscion jamaicensis & goete & CJ & AF \\
\hline Stellifer stellifer & cangoá & SS & AF \\
\hline Stellifer rastrifer & cangoá & SR & $\mathrm{AF} / \mathrm{AP}$ \\
\hline Stellifer brasiliensis & cangoá & SB & $\mathbf{A F} / \mathbf{A P}$ \\
\hline Ophioscion punctatissimus & canguá & OP & AF/AP \\
\hline Bairdiella ronchus & cangauá & BR & AF \\
\hline
\end{tabular}

Nos Arrastos de Fundo, seis espécies, Stellifer rastrifer, Isopisthus parvipinnis, Paralonchurus brasiliensis, Micropogonias furnieri, Stellifer brasiliensis e Menticinhus americanus, corresponderam a mais de $90,0 \%$ do total capturado em número, da famflia Sciaenidae (Fig. 3.5).

Nos Arrastos de Praia, apenas três espécies, Menticirrhus littoralis, Micropogonias furnieri e Menticirmus americanus, corresponderam a $98,0 \%$ do total capturado em número, dentre os Sciaenidae (Fig. 4.5).

Stellifer rastrifer (cangoá) foi a espécie mais abundante nos arrastos de fundo, correspondendo a
42,3\% em número do total capturado, com contribuição mais significativa à captura total no outono. Sua captura nos setores de amostragem ao longo das estaçōes do ano, revelou uma maior abundância no outono nos setores A e B, passando a ocupar o setor $\mathbf{C}$ no inverno, com capturas inexpressivas no setor A. Esse fato tornou-se mais evidente na primavera, quando nenhum exemplar foi capturado nesse setor. No verão, a espécie foi mais abundante na porção mediana da bafa e com alguns registros no setor A, passando a ocupar, no outono seguinte, novamente os setores A e B. Nas amostras com arrastos de praia, foram capturados somente treze indivíduos, sem significância (Figs 3.5, 3.6, 5.1 e 5.2). 
O decréscimo bem acentuado de sua captura na primavera pode estar relacionado com um padrão de emigraçāo em massa dos indivíduos, saindo da baía em direção à águas costeiras adjacentes, pela proximidade da época de reproduçāo que, segundo Sinque (1977), ocorre no verāo.

Isopisthus parvipinnis (tortinha) foi a segunda espécie mais abundante nos arrastos de fundo, correspondendo a $16,6 \%$ em número, com capturas mais expressivas no inverno e primavera. Ao longo das estações do ano, apresentou maiores capturas no setor A durante o outono. No setor B, as maiores capturas ocorreram durante o inverno e primavera, concentrando-se nos setores A e B durante o verảo, com capturas mínimas no setor C. Nas amostras de praia, foi capturada somente no outono de 1985, num total de três indivíduos (Figs 3.5, $3.6,5.1$ e 5.2 ).

Grandes capturas da espécie no setor externo, no outono, e a maior abundância, no inverno e primavera estiveram, possivelmente, relacionadas com uma desova única e prolongada a partir da primavera, na regiảo costeira adjacente à Baía de Santos (Soares, 1983).

Paralonchurus brasiliensis (maria-luísa) foi a terceira espécie mais capturada $(15,1 \%$ da captura total), com capturas mais consistentes na primavera e verão. A espécie pareceu se concentrar mais no setor $\mathbf{A}$ ao longo do ano, ocupando também o setor B durante o outono e primavera. Nas coletas com arrastos de praia, foi capturado um único indivíduo no verāo (Figs 3.5, 3.6, 5.1 e 5.2).

Maiores capturas foram obtidas no verāo-outono por Barbieri (1986) para a população da Lagoa dos Patos (RS). A discrepância entre os resultados esteve relacionada à abordagem de populaçōes distintas, já que a espécie se diferencia em duas populações na costa sul-sudeste do Brasil (Vargas, 1976).

Micropogonias fumieri (corvina) foi a quarta espécie mais abundante nas amostras com arrasto de fundo, correspondendo a 7,6 \% das capturas; sua captura foi mais significativa no verão. Maiores capturas foram obtidas nos setores mais internos a partir da primavera, tendência essa, evidente no verão quando foi abundante no setor C; durante o outono tende a ocupar o setor $\mathbf{B}$, alcançando o setor externo A no inverno. Nas amostras de praia, a corvina foi a segunda espécie mais abundante correspondendo a $17,9 \%$ do total capturado. Embora tenha ocorrido o ano todo, sua abundância foi muito superior na primavera (Figs 3.5,3.6, 4.5, 4.6,5.1 e 5.2). Tais resultados indicaram que o deslocamento da espécie dos setores medianos e externo da baía no outono e inverno, e as grandes capturas de verāo na região de praias e setores internos da baía, estiveram relacionados com uma desova de inverno-primavera na regiāo costeira adjacente, citada por Vazzoler (1971).

Stellifer brasiliensis (cangoa) foi a quinta espécie mais abundante nos arrastos de fundo, correspondendo a 7,5\% do total capturado, sendo mais representativa no verão e outono. Para Coelho et al. (1987), no litoral de São Paulo, a espécie foi mais abundante no verão. A variação espacial dessa espécie nâo foi marcante ao longo das estaçōes do ano; contudo, pareceu se concentrar mais no setor B durante a primavera, ocupando igualmente os setores mais internos no verão e voltando a se concentrar nos setores A e B durante o outono-inverno. Nos arrastos de praia foram capturados apenas dois indivíduos, no outono e verão (Figs 3.5, 3.6, 6.1 e 6.2).
Menticirmus americanus (betara) foi a espécie menos abundante dentre os cienídeos, correspondendo a 1,2\% do total capturado e com maior representatividade no verão. As maiores capturas da espécie foram obtidas no outono no setor externo A. As capturas foram uniformes em toda a baía durante o inverno e primavera e, do final desta ao verão, as maiores capturas estiveram associadas ao setor interno C. Nos arrastos de praia, a betara foi a terceira espécie mais abundante $(7,2 \%$ das capturas), com capturas irregulares ao longo do ano e um único pico significante na primavera, quando suas captura foi mais representativa (Figs 3.5, 3.6, 4.5, 4.6, 6.1 e 6.2).

A maior captura da espécie com arrastos de fundo no outono no setor externo e com arrastos de praia na primavera, estiver relacionada, provavelmente, com uma desova de inverno- primavera, citada por Alvitres Castillo (1986), na regiāo costeira adjacente e, posterior recrutamento dos jovens do ano às àreas marginais de praia.

Menticirrhus littoralis (betara) foi a espécie dominante nas capturas nas praias $(\mathbf{7 2 , 8 \% )}$, ocorrendo durante todo o ano e sendo mais abundante no outono e inverno. Apresentou um declínio de sua representatividade apenas na primavera, quando as duas outras espécies mais abundantes (M. furnieri e $M$. americanus) contribuíram com mais de $50 \%$ do total capturado. Esta espécie foi capturada nos arrastos de fundo em uma única ocasiảo, com quatro exemplares no outono de 1985 (Figs 4.5, 4.6, 6.1 e 6.2).

Segundo Chao (1978) e Menezes \& Figueiredo (1980), os juvenis dessa espécie habitam a zona de arrebentação de praias arenosas, sendo abundantes em águas rasas. A dominância da espécie dentre os cienídeos e maiores capturas no outono foram relatadas por Cunha (1981) para a zona de arrebentação da praia do Cassino (RS).

Umbrina coroides (castanha-riscada) foi capturada uma única vez com um exemplar no verãono setor externo A. Nos arrastos de praia foi a quarta espécie mais abundante, embora tenham sido capturados somente 39 exemplares ao longo do período de estudo, com um pico no verão e decrescendo em abundância, a partir deste, até a primavera (Figs 6.1 e 6.2).

Ophioscion punctatissimus (canguá) apresentou baixas capturas nos arrastos de fundo (apenas 10 exemplares). Ocupou, preferencialmente, os setores B e C durante o outono. Nos arrastos de praia foram capturados 21 exemplares a partir da primavera, com um pico no outono de 1986 (Figs 6.1 e 6.2).

Bairdiella ronchus (cangauá) foi a sexta espécie mais capturada nos arrastos de fundo, com 454 indivíduos, ocorrendo em meses esparsos. Esteve associada principalmente ao setor $B$, com um pico de abundância no outono de 1986 no setor A (Fig. 7).

Macrodon ancylodon (pescada-foguete) foi a sétima espécie em abundância nos arrastos de fundo, com 387 exemplares capturados, mas com capturas expressivas somente no inverno no setor externo $\mathbf{A}$ e decrescendo rapidamente, em abundância, ao longo do tempo (Fig. 7).

Stellifer stellifer (cangoá) foi a oitava espécie mais abundante nos arrastos de fundo, com 270 exemplares, estando mais associada ao lado oeste dos setores B e C, no outono e inverno (Fig. 7). 

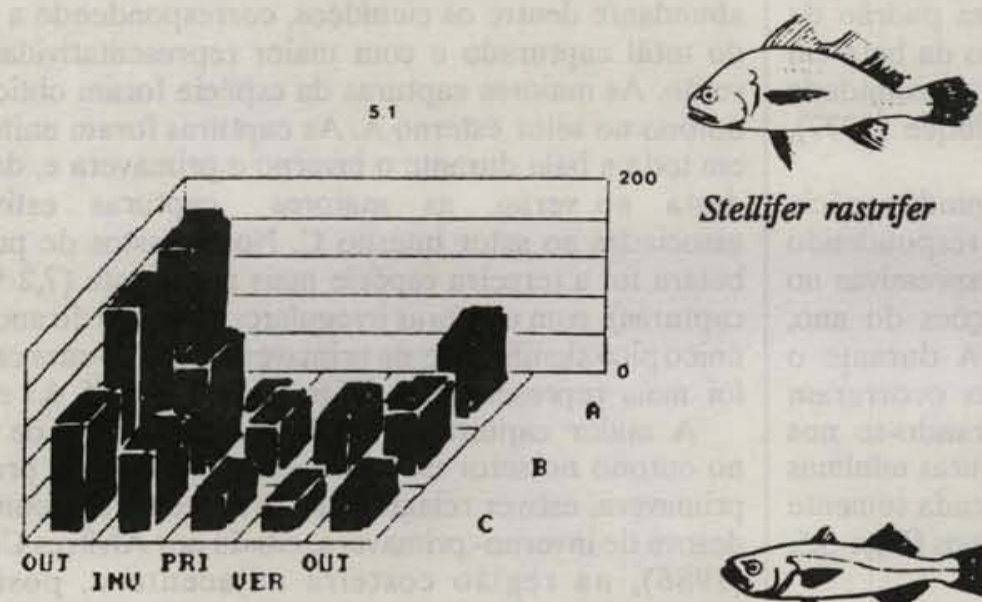

Stellifer rastrifer
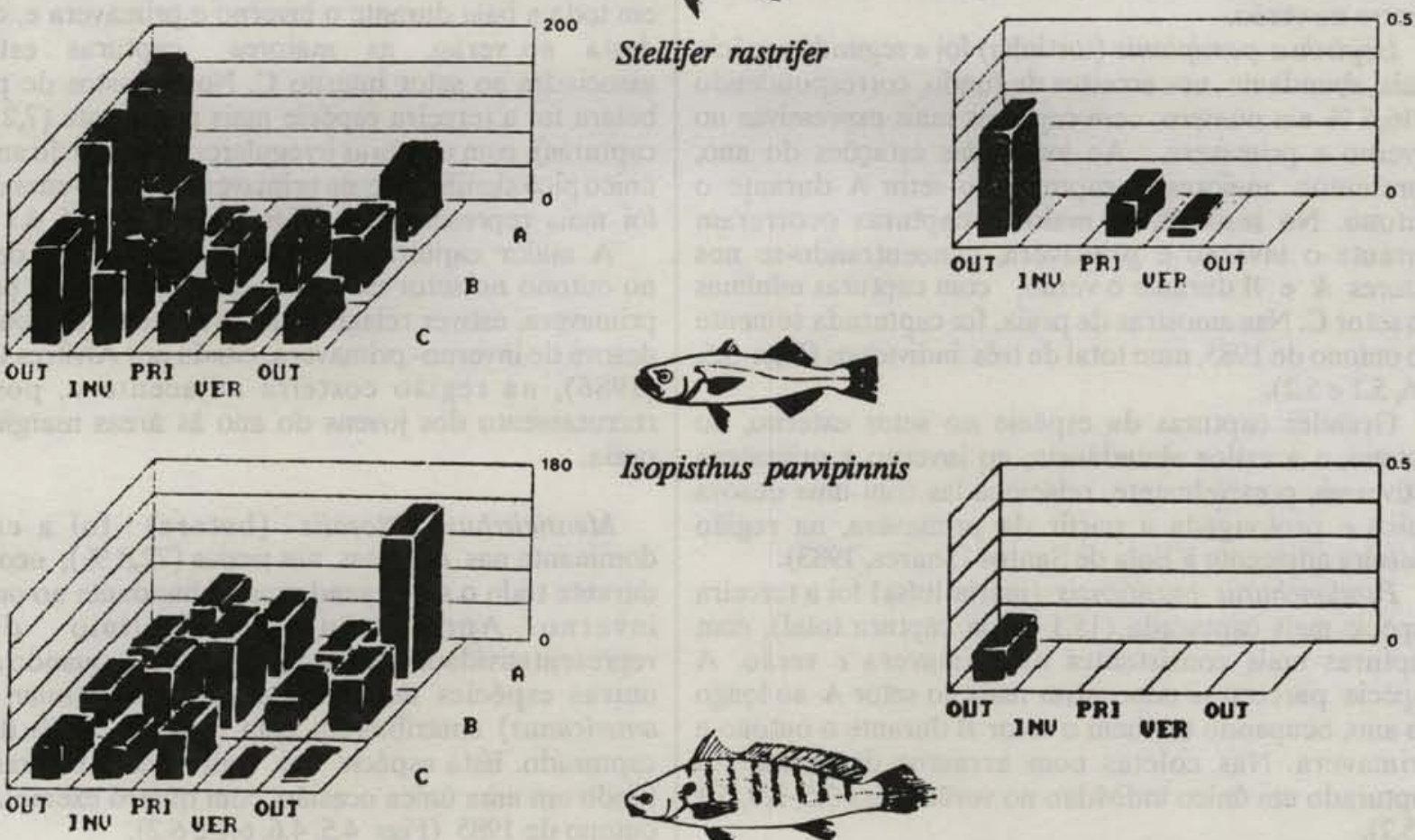

Isopisthus parvipinnis
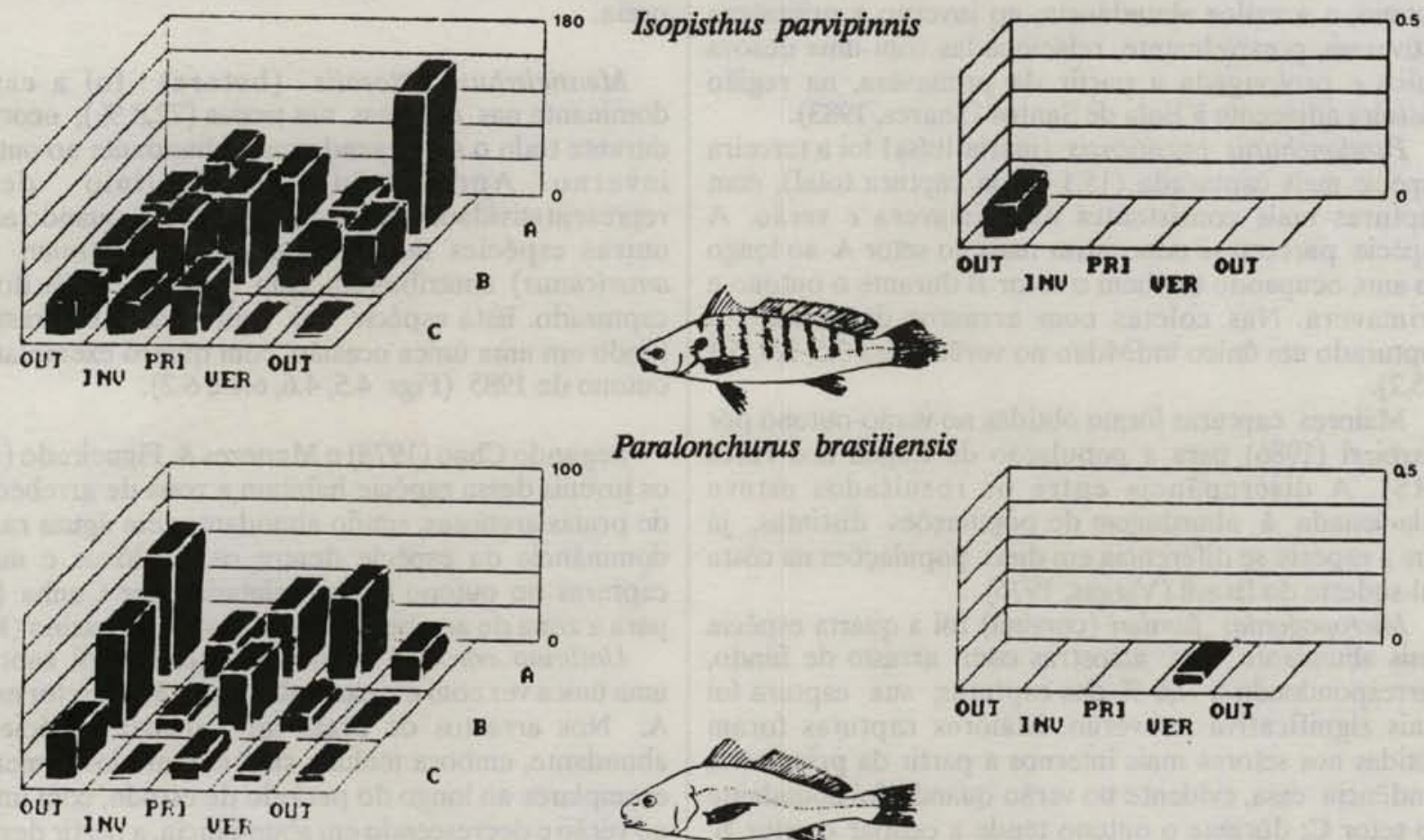

Paralonchurus brasiliensis
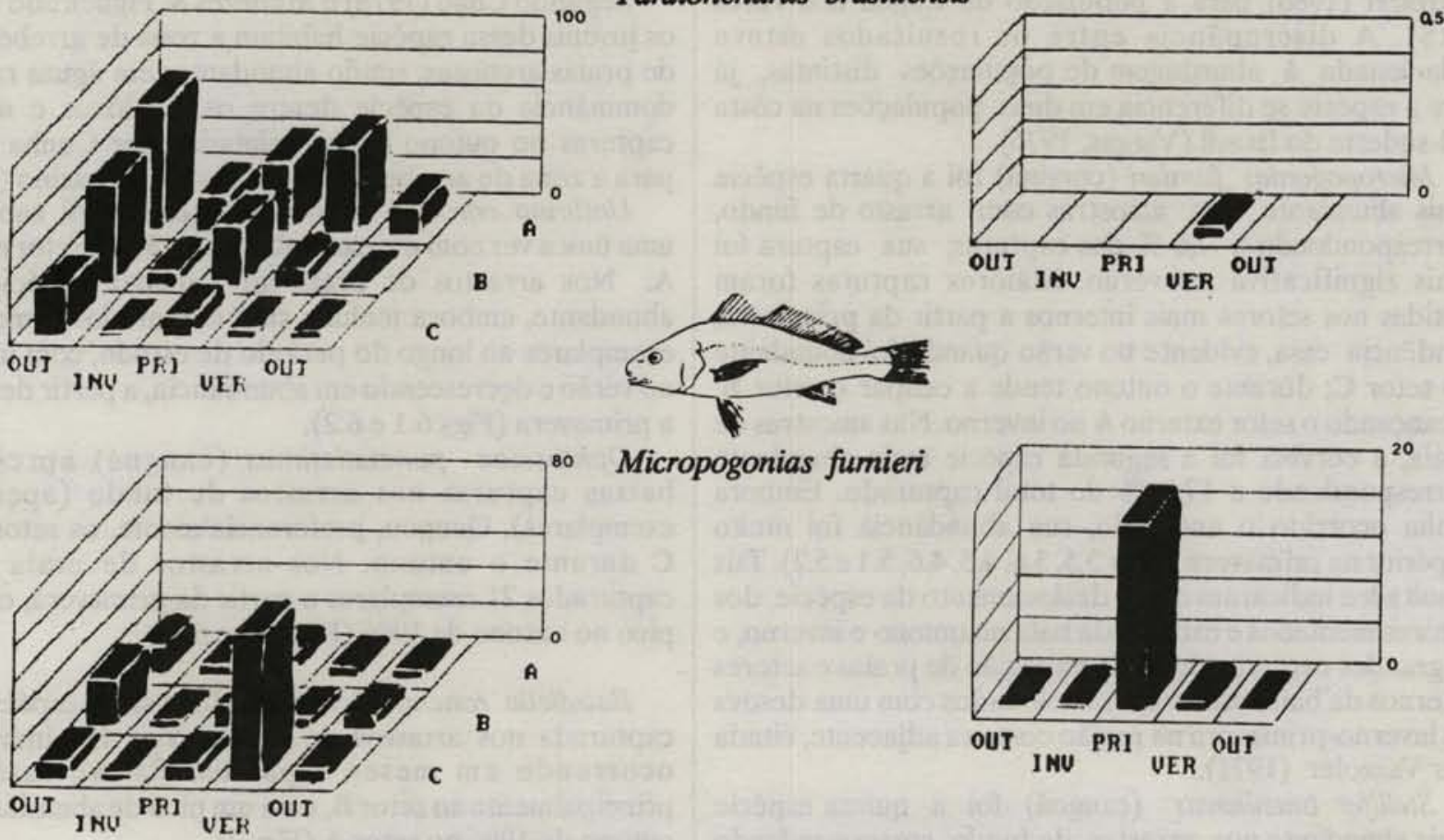

Micropogonias fumieri

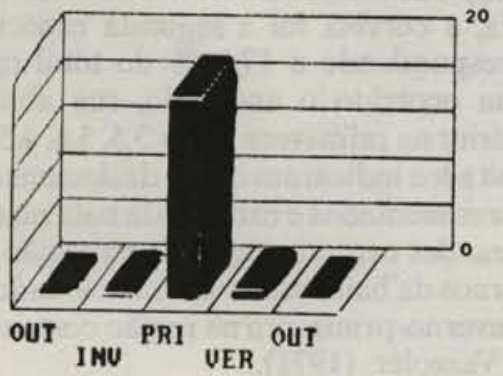

Fig. 5. Abundância relativa (CPUE) expressa em número de exemplares das capturas médias sazonais por setor de coleta, em amostras com arrastos de fundo (5.1) e de praia (5.2) de Stellifer rastrifer, Isopisthus parvipinnis, Paralonchurus brasiliensis e Micropogonias furnieri. 

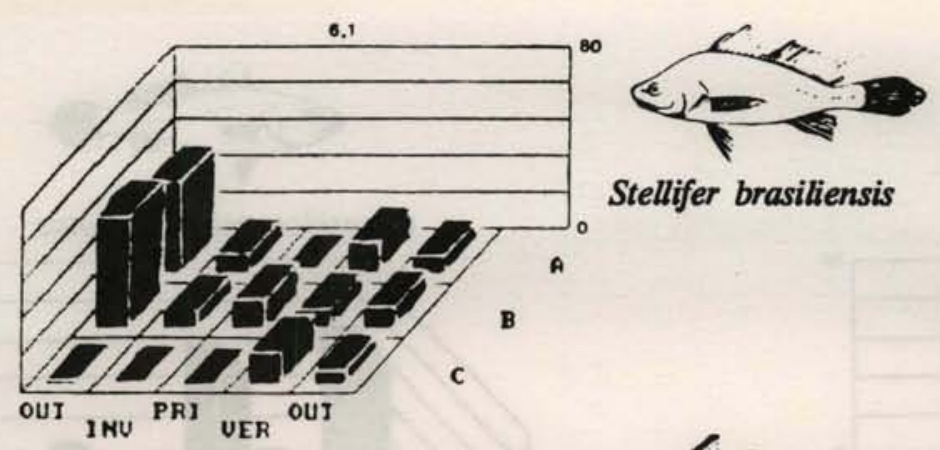

Stellifer brasiliensis
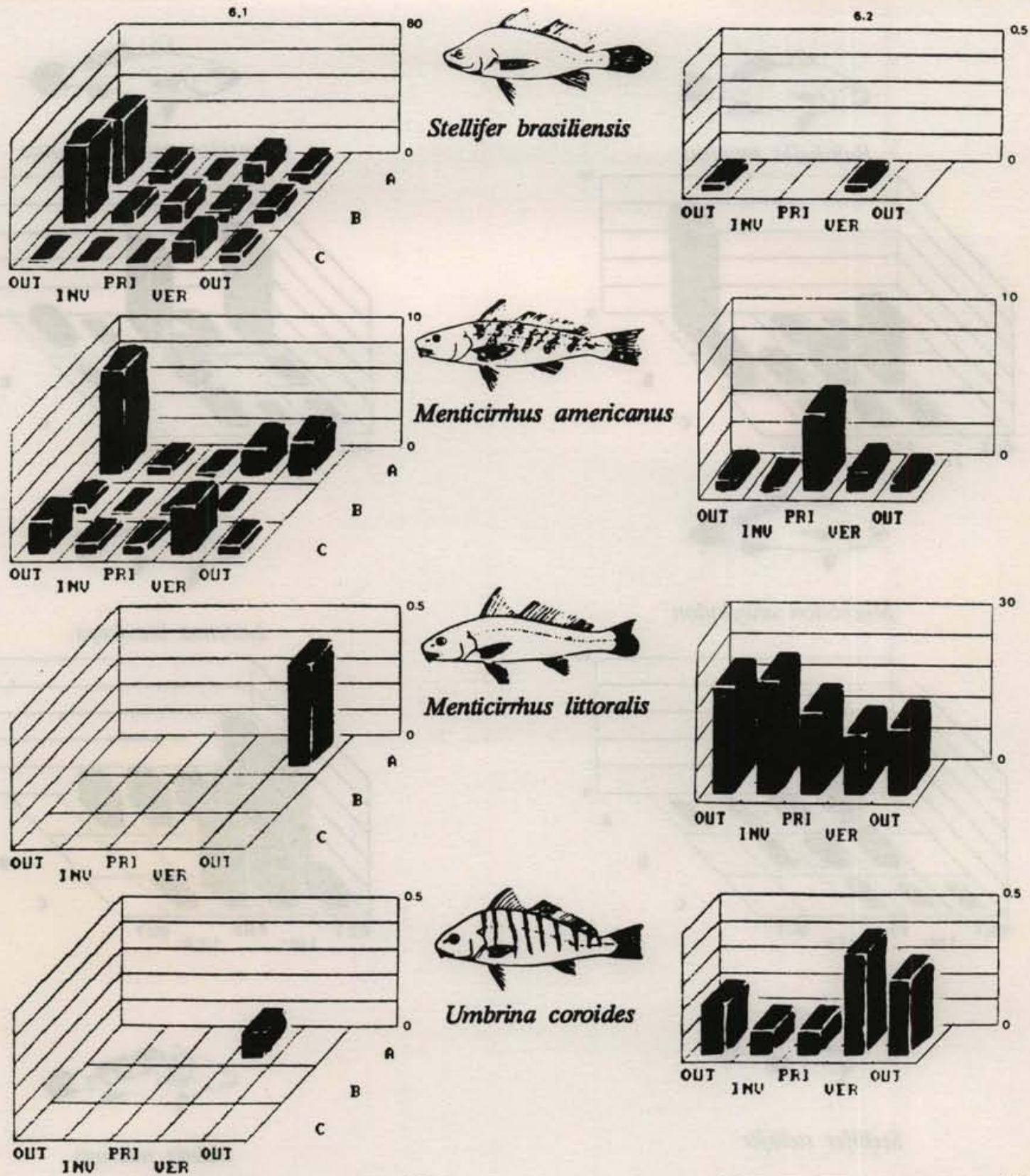

Umbrina coroides
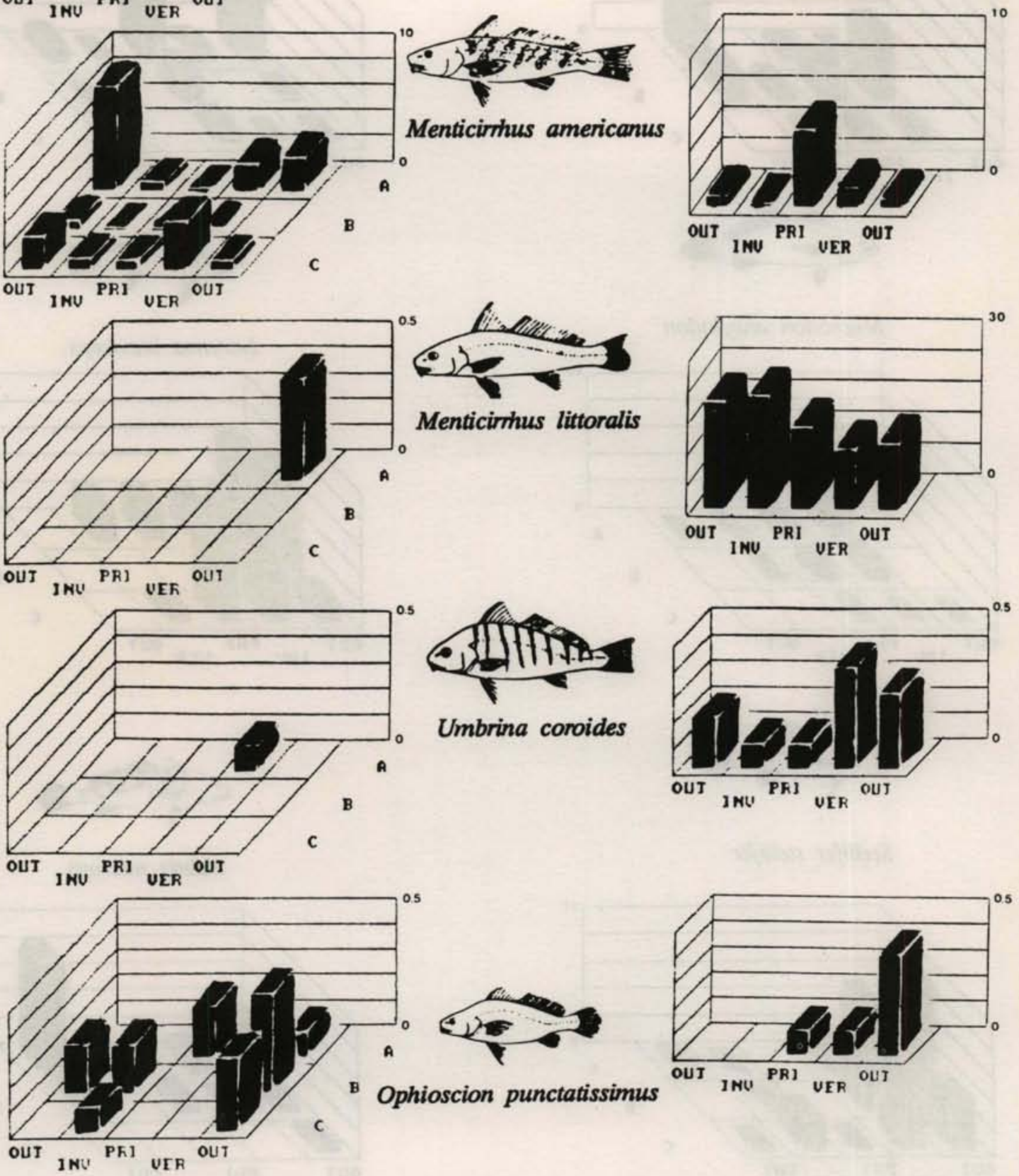

Fig. 6. Abundância relativa (CPUE) expressa em número de exemplares das capturas médias sazonais por setor de coleta, em amostras comarrastos de fundo (6.1) e de praia (6.2) de Stellifer brasiliensis, Menticirrhus americanus, Menticirrhus littoralis, Umbrina coroides e Ophioscion puncatissimus. 

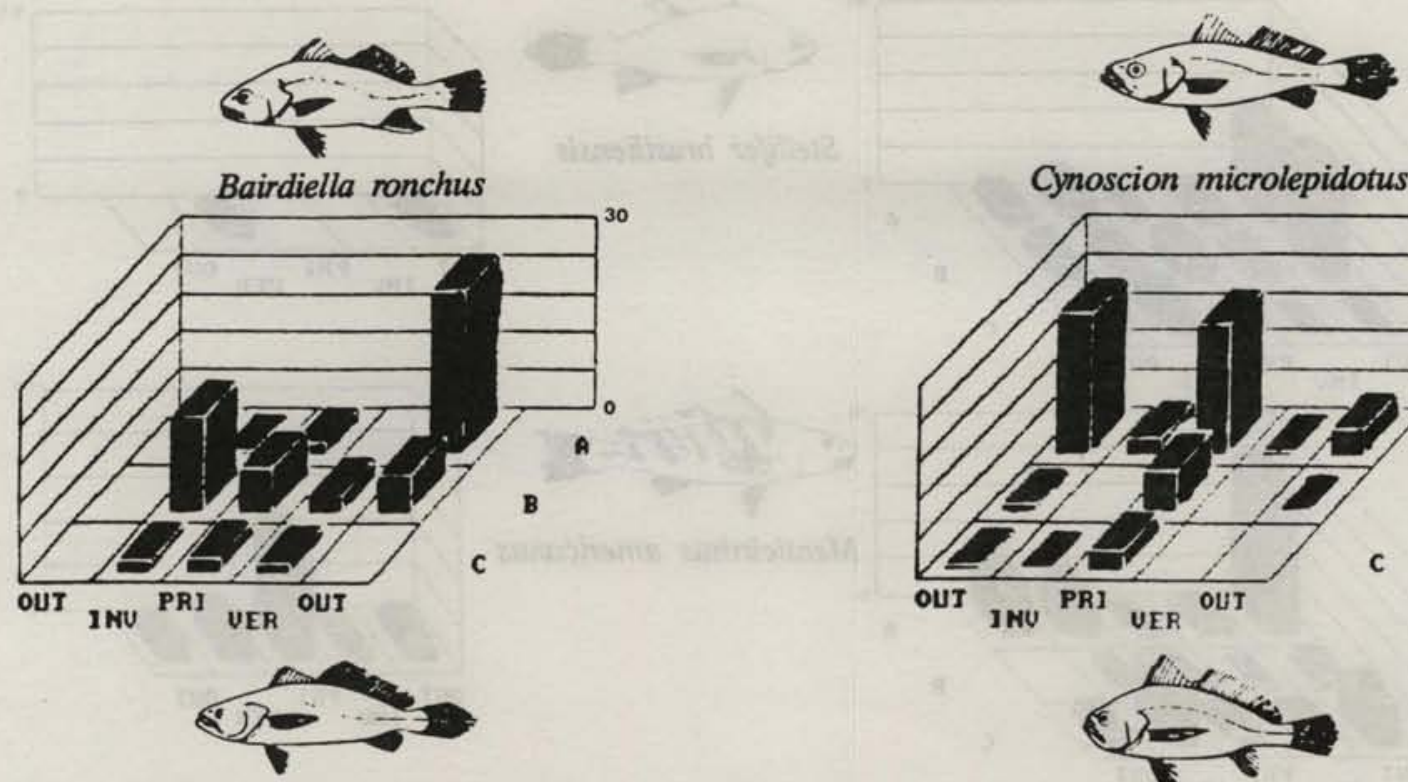

Cynoscion microlepidotus
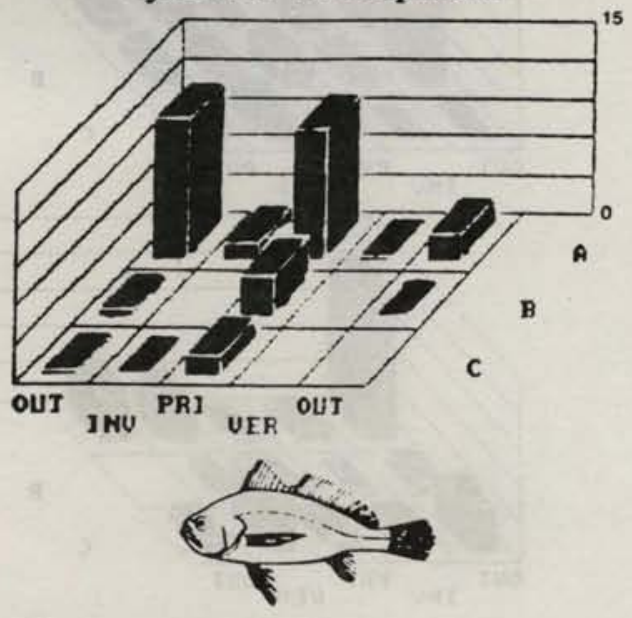

Macrodon ancylodon
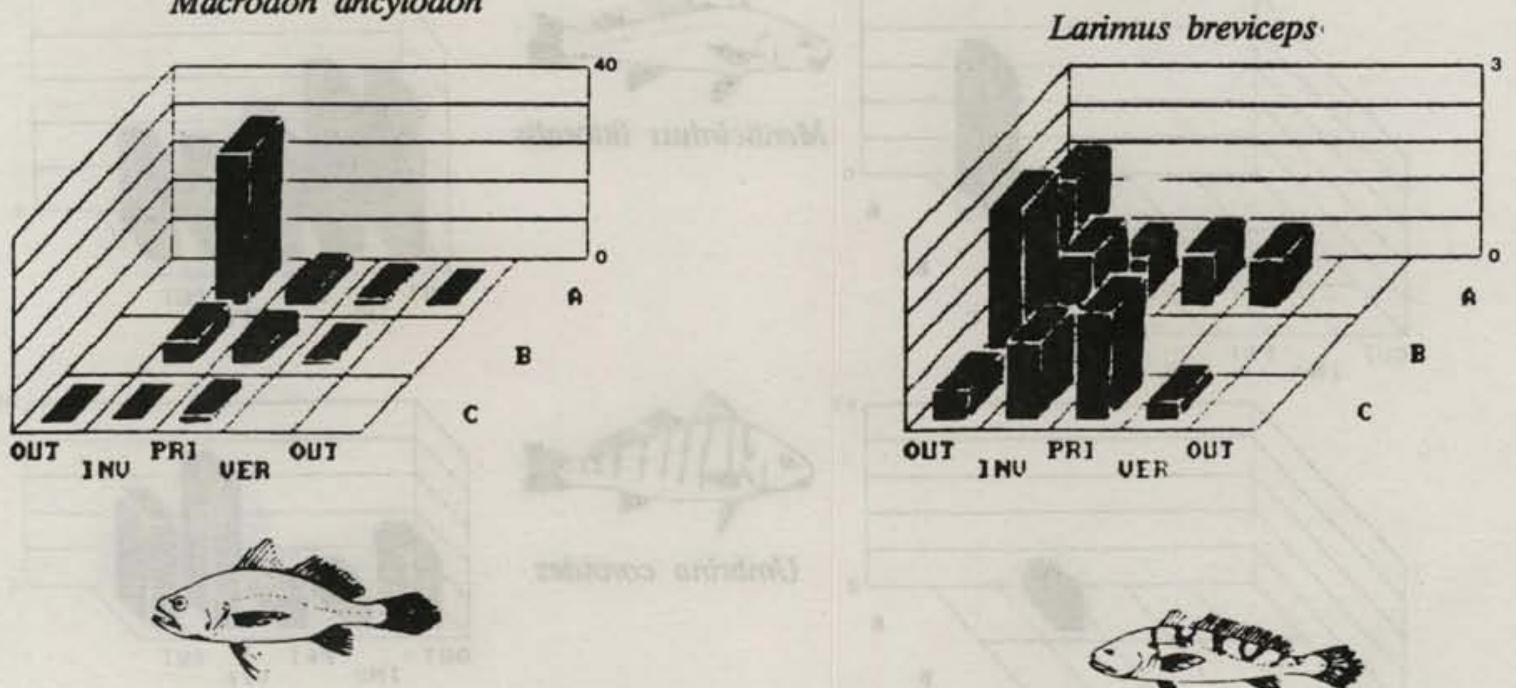

Stellifer stellifer
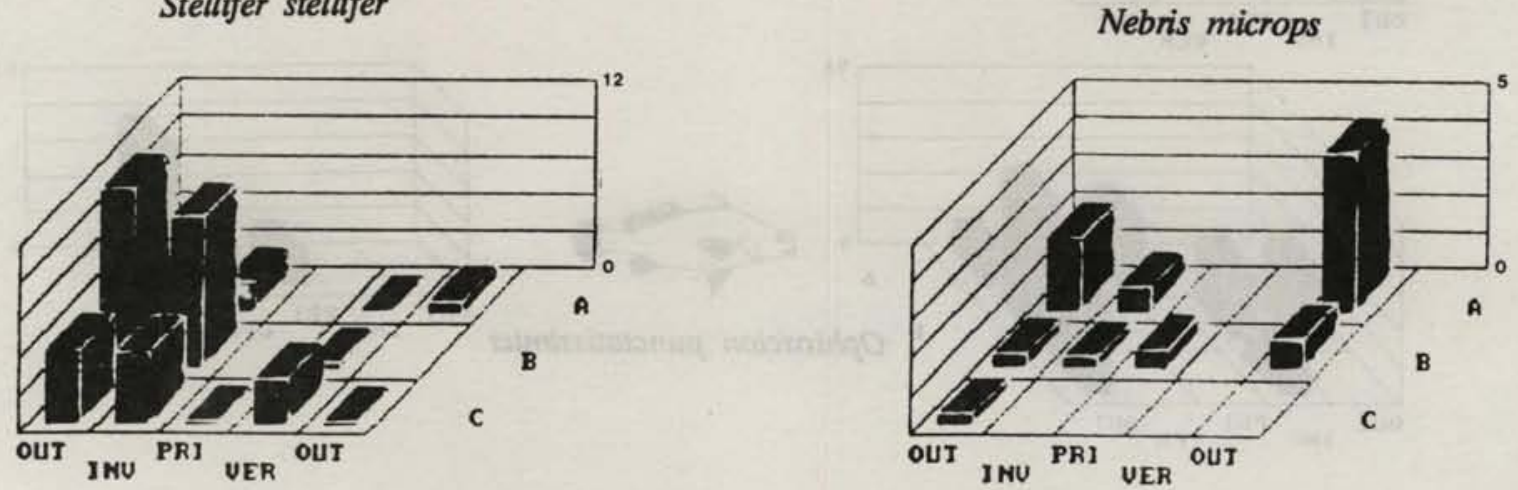

Fig. 7. Abundância relativa (CPUE) expressa em número de exemplares das capturas médias sazonais por setor de coleta, em amostras com arrastos de fundo de Bairdiella ronchus, Macrodon ancylodon, Stellifer stellifer, Cynoscion microlepidotus, Larimus breviceps e Nebris microps. 
Cynoscion microlepidotus (pescada-dentāo) foi a nona espécie, em abundância, nas capturas com arrastos de fundo, com 227 exemplares capturados principalmente no setor externo $\mathbf{A}$, no outono e primavera (Fig. 7).

Larimus breviceps (oveva), com apenas 84 exemplares capturados nos arrastos de fundo, foi mais abundante nos setores A e B, notadamente no outono, aumentando entāo sua captura no setor $\mathbf{C}$, do inverno-primavera ao verāo (Fig. 7).

Nebris microps (pescada-banana), com 75 exemplares capturados, esteve praticamente restrita aos setores A e B, principalmente no outono (Fig. 7).

Cynoscion virescens (pescada-cambucu) teve capturas mais expressivas no setor $\mathbf{A}$, no outono-inverno, ocupando o setor B na primavera-verão, num total de 66 indivíduos (Fig. 8).

Ctenosciaena gracilicimhus (cangaua) esteve pouco representada na região (total de 53 exemplares), com capturas restritas ao setor $\mathbf{A}$ no verảo e $\mathbf{B}$ no outono (Fig. 8).

Cynoscion jamaicensis (goete) foi pouco capturada, com 34 exemplares ocorrendo no setor externo A no verāo-outono (Fig. 8).

Cynoscion leiarchus (pescada-branca) ocorreu somente no inverno no setor B, com apenas dois exemplares (Fig. 8).

Pogonias cromis (miraguaia) foi capturada em uma única ocasião nos arrastos de fundo, com um exemplar no setor interno C no outono de 1985 (Fig. 8).

De modo geral, pode-se verificar que dentre os cienídeos mais abundantes e freqüentes, $M$. fumieri e $M$. americanus exploraram vários tipos de habitats e foram capturadas mais eficientemente em arrastos de fundo, demonstrando assim, possuirem uma maior afinidade para com a regiảo demersal. Porém, como foram também capturadas significativamente nos arrastos de praia, pode-se concluir que essas espécies também ocuparam faixas superiores da coluna de água, utilizando as regiōes marginais rasas, pelo menos durante parte de sua permanência no ecossistema.

As capturas expressivas de $S$. rastrifer, $I$. parvipinnis, $P$. brasiliensis e $S$. brasiliensis apenas nos arrastos de fundo, indicaram a ocupação preferencial da zona demersal da Baía de Santos.

A ocorrência de $M$. littoralis somente nas amostras com arrastos de praia poderia indicar uma utilização espacial mais restrita, com um padrāo de emigraçāo massiva da região. Contudo, a corroboração de tal hipótese depende de um estudo melhor estruturado, envolvendo, por exemplo, horários e aparelhos de amostragem diversos.

Quanto às demais espécies de cienídeos, menos abundantes, pode-se separá-las em três grupos principais:

- O grupo das "pescadas" (M. ancylodon, $C$. microlepidotus, C.virescens, C.jamaicensis e N.microps), as quais for am capturadas apenas nas amostras com arrastos de fundo, preferencialmente no setor externo, entre o outono e a primavera (com maior intensidade no inverno).
- O segundo grupo (B. ronchus, S. stellifer, C. gracilicirrhus e L. breviceps), ocorreu também nos setores mediano e interno, demonstrando um padrão de utilizaçāo espacial mais amplo dentro da baía, embora de ocorrência sazonal.

- O terceiro grupo ( $U$. coroides, $O$. punctatissimus, $C$. leiarchus e $P$. cromis) foi o menos abundante e freqüente, com capturas ocasionais. As duas primeiras espécies desse grupo salientaram-se por ocorrerem também nos arrastos de praia, indicando uma utilização das regiōes marginais mais rasas, pelo menos durante uma fase do crescimento.

\section{Análise em componentes principais}

As espécies de Sciaenidae mais abundantes que ocorreram nas amostras com arrasto de fundo e de praia foram submetidas à uma análise multifatorial em função das variáveis temporais, espaciais e hidrográficas e os resultados destacaram dois fatores principais responsáveis por $61,3 \%$ e $78,6 \%$ da variância total dos dados nos arrastos de fundo e de praia, respectivamente, representados pelos planos fatoriais 1 e 2 (Fig. 9).

Nesses planos estão projetados os vetores-espécies, em relação ao círculo unitário e ao círculo de equilibrio, de raio correspondente ao número de dimensōes e componentes principais utilizados.

Para os Arrastos de Fundo, o componente principal 1 foi responsável por $40,2 \%$ da variância entre as espécies e mostrou-se altamente correlacionado com a profundidade e as salinidades das águas de superfície e de fundo; o componente principal 2 foi responsável por $21,1 \%$ da variância e apresentou alta correlação com as estações do ano (verāo-inverno), com as temperaturas das águas de superfície e de fundo e com a salinidade da água de superfície.

Analisando-se o conjunto de vetores verificou-se que houve uma separação gradual entre as espécies em relaçāo aos componentes. Em relação ao componente principal 1, $P$. brasiliensis, $S$. brasiliensis e $I$. parvipinnis, ocuparam águas preferencialmente mais profundas e salgadas em comparação com $M$. americanus e $M$. fumieri. $S$. rastrifer ocupou uma posição intermediária entre esses dois grupos (Fig. 9.1).

Em relação ao componente principal 2, I. parvipinnis e $S$. rastrifer ocorreram em águas mais frias de inverno, em comparação $\operatorname{com} M$. furnieri e $M$. americanus, que preferiram águas mais quentes no verão. $P$. brasiliensis e $S$. brasiliensis ocuparam uma posição intermediária entre os dois grupos supracitados (Fig. 9.1).

Para os Arrastos de Praia, o componente principal 1 foi responsável por $44,8 \%$ da variância entre as espécies, estando correlacionado com as áreas de coleta. $\mathbf{O}$ componente principal 2 foi responsável por $33,7 \%$ da variância e apresentou alta correlaçāo com as estaçōes do ano (verão-inverno) e com a temperatura da água de superfície. 


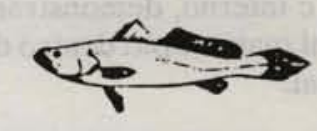

Cynoscion virescens
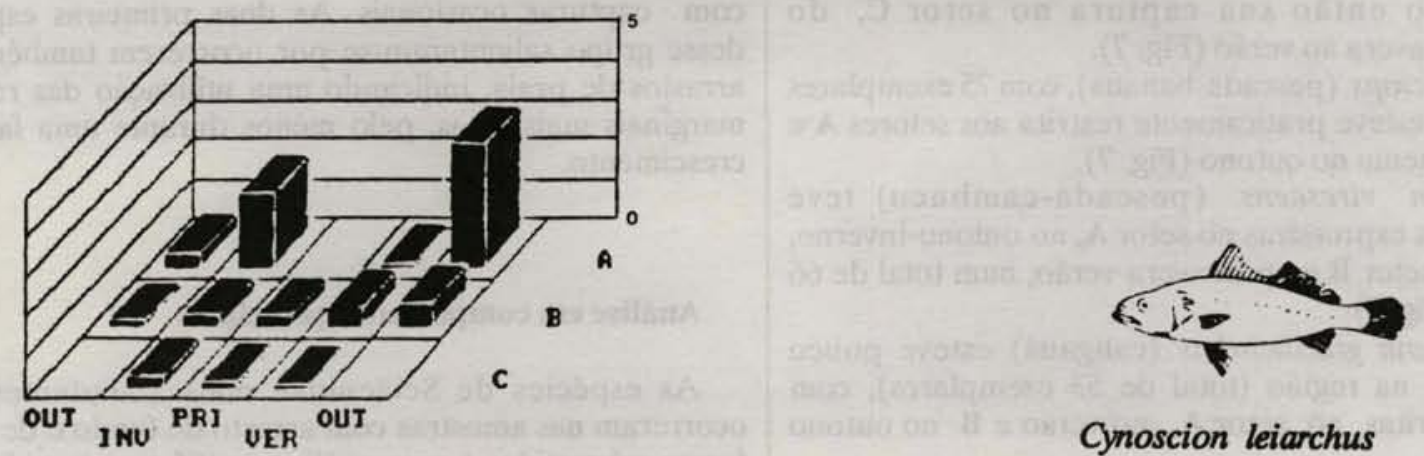

Cynoscion leiarchus

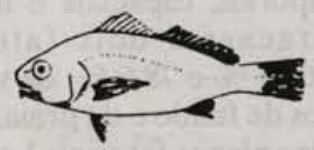

Ctenosciaena gracilicirmus
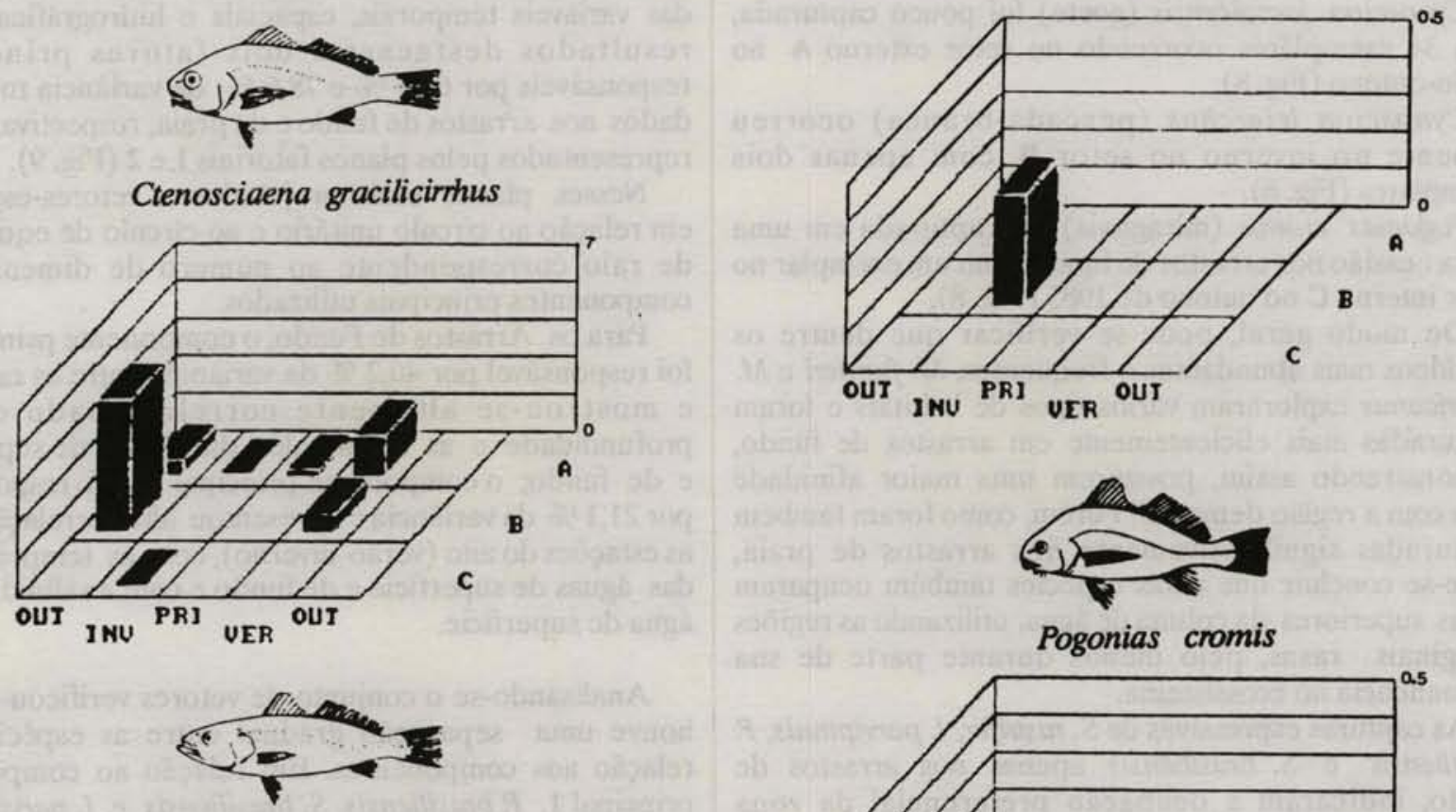

Cynoscion jamaicensis
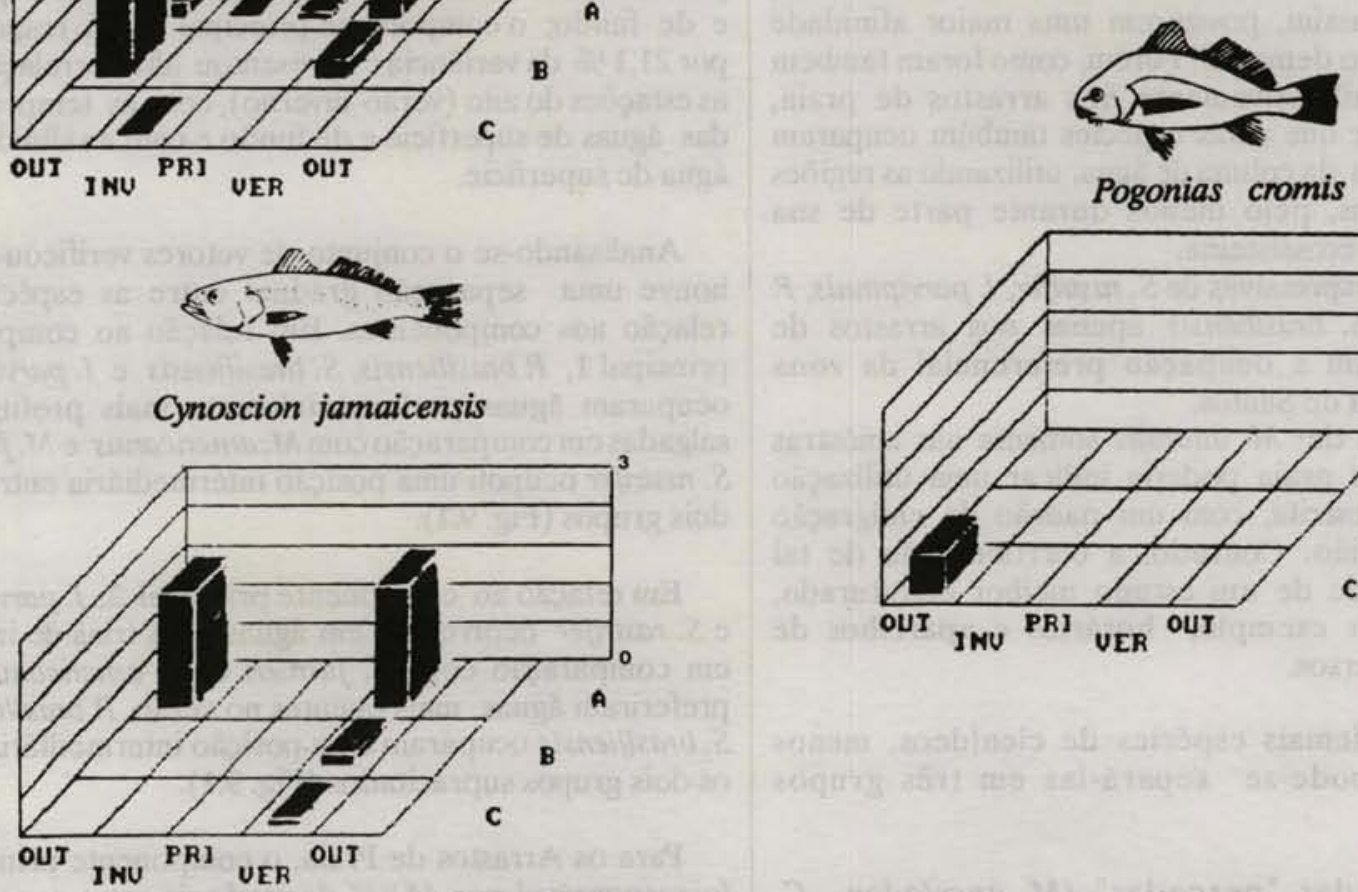

Pogonias cromis

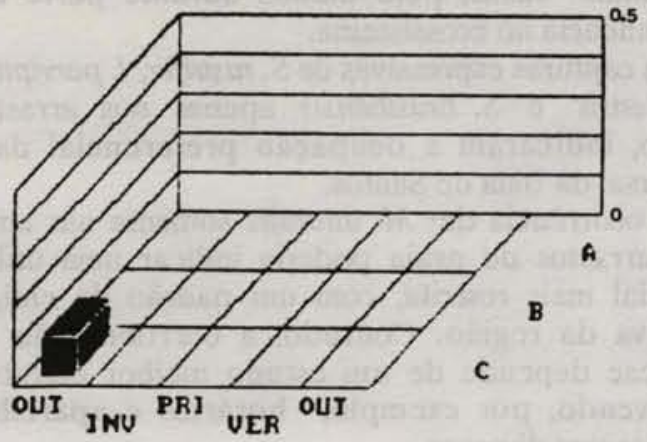

Fig. 8. Abundância relativa (CPUE) expressa em número de exemplares das capturas médias sazonais por setor de coleta, em amostras com arrastos de fundo de Cynoscion virescens, Ctenosciaena gracilicirrhus, Cynoscion jamaicensis, Cynoscion leiarchus e Pogonias cromis. 

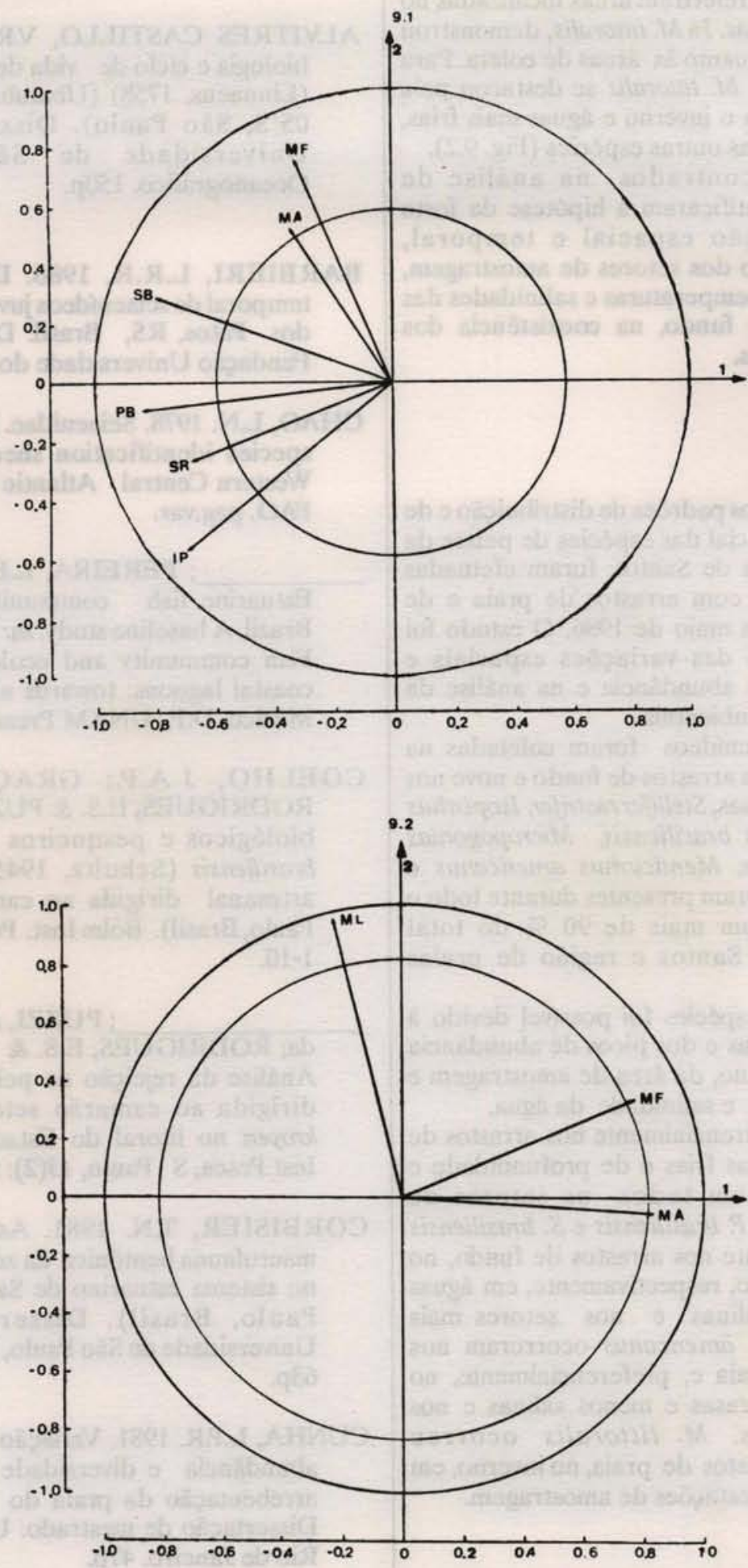

Fig. 9. Posição dos vetores-espécies em relação aos componentes principais 1 e 2, em amostras com arrastos de fundo (9.1) e de praia (9.2). SR, IP, PB, MF, SB, MA e ML são as espécies (vide Tab. 1). Círculo externo: círculo de raio unitário (máximovalor possível de ser atribuido a um descritor após análise da matriz de correlação); ćŕrculo interno: ćŕrculo de equilibrio de raio $\sqrt{\mathrm{d} / \mathrm{n}}(0,58$ para as amostras com arrasto de fundo e 0,82 para as amostras com arrasto de praia). 
$\mathrm{Da}$ análise do conjunto de vetores, pode-se verificar que, em relação ao componente principal 1, $M$. americanus e $M$. fumieri preferiram áreas localizadas no lado leste da regiāo de praias. Já $M$. littoralis, demonstrou uma maior uniformidade quanto às áreas de coleta. Para o componente principal 2, $M$. littoralis se destacou pela grande afinidade para com o inverno e águas mais frias, em comparação com as duas outras espécies (Fig. 9.2).

Os resultados encontrados na análise de componentes principais ratificaram a hipótese da forte influência da repartição espacial e temporal, principalmente em função dos setores de amostragem, das estaçōes do ano e das temperaturas e salinidades das águas de superfície e de fundo, na coexistência dos cienídeos na Baía de Santos.

\section{Resumo}

A fim de se determinar os padrōes de distribuição e de repartiçāo temporal e espacial das espécies de peixes da familia Sciaenidae na Baía de Santos, foram efetuadas amostras mensais diurnas com arrastos de praia e de fundo, de março de 1985 a maio de 1986. O estudo foi baseado na comparação das variaçōes espaciais e temporais da ocorrência e abundância e na análise da influência de parâmetros ambientais.

Vinte espécies de cienídeos foram coletadas na regiāo, todas ocorrendo nos arrastos de fundo e nove nos arrastos de praia. Dentre essas, Stellifer rastrifer, Isopisthus parvipinnis, Paralonchurus brasiliensis, Micropogonias fumieri, Stellifer brasiliensis, Menticirmus americanus e Menticirmus littoralis, estiveram presentes durante todo o período, contribuíndo com mais de $90 \%$ do total capturado na Baía de Santos e regiāo de praias adjacentes.

A coexistência dessas espécies foi possível devido à alternância das ocorrências e dos picos de abundância em funçāo das épocas do ano, da área de amostragem e da variaçāo da temperatura e salinidade da água.

$S$. rastrifer ocorreu preferencialmente nos arrastos de fundo, no inverno, em águas frias e de profundidade e salinidade medianas e em todos os setores de amostragem. I. parvipinnis, $P$. brasiliensis e $S$. brasiliensis ocorreram preferencialmente nos arrastos de fundo, no inverno, primavera e outono, respectivamente, em águas frias, profundas e mais salinas e nos setores mais externos. $M$. furnieri e $M$. americamus ocorreram nos arrastos de fundo e de praia e, preferencialmente, no verão, em águas quentes, rasas e menos salinas e nos setores mais internos. M. littoralis ocorreu preferencialmente nos arrastos de praia, no inverno, em águas frias e em todas as estaçōes de amostragem.

\section{Agradecimentos}

Os autores agradecem à Oscar Barbosa e Edgar Borges, da Base de Santos do Instituto Oceanográfico da Universidade de São Paulo, e à tripulação do B/Pesq. "Veliger II", pela colaboraçāo nas coletas. Aos colegas Francisco Borba Ribeiro Neto e Joāo Marcos Miragaia Schmiegelow, pelo apoio nos trabalhos de campo e de laboratório.

\section{Referências bibliográficas}

ALVITRES CASTILLO, V.R. 1986. Estudo sobre a biologia e ciclo de vida de Menticirmus americanus (Linnaeus, 1758) (Ubatuba 23⒊' - Cananéia $25^{\circ}$ 05'S, São Paulo). Dissertação de mestrado. Universidade de São Paulo, Instituto Oceanográfico. 150p.

BARBIERI, L.R.R. 1986. Distribuição espacial e temporal de sciaenídeos juvenis no estuário da Lagoa dos Patos, RS, Brasil. Dissertação de mestrado. Fundação Universidade do Rio Grande. 98p.

CHAO, L.N. 1978. Sciaenidae. In: Fischer, W., ed. FAO species identification sheets for fishery purpose. Western Central Atlantic (fishing area 31). Rome, FAO. pag.var.

; PEREIRA, L.E. \& VIEIRA, J.P. 1985. Estuarine fish community of the Patos Lagoon, Brazil. A baseline study. In: Yáñez-Arancíbia, A., ed. Fish community and ecology in estuaries and coastal lagoons: towards an ecosystem integration. México, D.F., UNAM Press. p.429-450.

COELHO, J.A.P.; GRAÇA LOPES, R. da; RODRIGUES, E.S. \& PUZZI, A. 1987. Aspectos biológicos e pesqueiros do Sciaenidae Stellifer brasiliensis (Schultz, 1945), presente na pesca artesanal dirigida ao camarão sete-barbas (São Paulo, Brasil). Bolm Inst. Pesca, S Paulo, 14 (único): 1-10.

; PUZZI, A.; GRACCA LOPES, R. da; RODRIGUES, E.S. \& PIETRO JR., O. 1986. Análise da rejeição de peixes na pesca artesanal dirigida ao camarão sete-barbas Xyphopenaeus kroyeri no litoral do Estado de São Paulo. Bolm Inst.Pesca, S Paulo, 13(2): 51-61.

CORBISIER, T.N. 1981. Aspectos ecológicos da macrofauna bentônica da zona entre-marés arenosa, no sistema estuarino de Santos (Estado de São Paulo, Brasil). Dissertação de mestrado. Universidade de São Paulo, Instituto Oceanográfico. 63p.

CUNHA, L.P.R. 1981. Variação sazonal da distribuição, abundância e diversidade dos peixes na zona de arrebentaçāo da praia do Cassino, R.S. - Brasil. Dissertação de mestrado. Universidade Federal do Rio de Janeiro. 47p.

CUNNINGHAM, P.T.M. 1983. Estudo comparativo da ictiofauna da costa oeste e Enseada das Palmas da Illa Anchieta, Enseada do Flamengo e Enseada da Fortaleza (Lat. $23^{\circ} 29^{\prime} \mathrm{S}-23^{\circ} 33^{\prime} \mathrm{S}$, Long. $\left.45^{\circ} 03^{\prime} \mathrm{W}-45^{\circ} 09^{\prime} \mathrm{W}\right)$, Ubatuba, Estado de São Paulo-Brasil. Tese de doutorado. Universidade de São Paulo, Instituto Oceanográfico. 133p. 
FÚlFARO, V.J. \& PONÇANO, W.L. 1976. Sedimentação atual do estuário e baía de Santos: um modelo geológico aplicado a projetos de expansão da zona portuária. In: CONGRESSO BRASILEIRO DE GEOLOGIA DE ENGENHARIA, 1., Rio de Janeiro, 1976. Anais. Rio de Janeiro, Associação Brasileira de Geologia de Engenharia.v.2, p.67-90.

GIANNINI, R. 1989. Distribuiçāo temporal e espacial e aspectos bioecológicos da família Sciaenidae na Baía de Santos, SP, Brasil. Dissertação de mestrado. Universidade de São Paulo, Instituto Oceanográfico. 203p.

LEGENDKE, L. \& LEGENDRE, P. 1983. Numerical ecology. New York, Elsevier. 420p.

MATSUURA, Y. 1977. O ciclo de vida da sardinha verdadeira (Introduçāo à oceanografia pesqueira). Publçāo. esp. Inst. oceanogr. Univ. S Paulo, (4):1-146.

\& NAKATANI, K. 1979. Ocorrência de larvas e jovens de peixes na Ilha Anchieta (SP), com aigumas anotaçōes sobre a morfologia da castanha Umbrina coroides Cuvier, 1830. Bolm Inst.oceanogr., S Paulo, 28(1): 165-183.

MENEZES, N.A. \& FIGUEIREDO, J.L. 1980. Manual de peixes marinhos do sudeste do Brasil. IV. Teleostei (3). São Paulo, Museu de Zoologia da Universidade de São Paulo. 96p.

MESQUITA, A.R. 1974. Report on the seasonal variations of coastal waters, Brazil (Lat. $24^{\circ} \mathrm{S}$ ). Relat.int.Inst.oceanogr. Univ. S Paulo, (1):1-36.

NONATO, E.F.; AMARAL, A.C.Z. \& FIGUEIREDO, J.L. 1983. Contribuição ao conhecimento da fauna de peixes do litoral norte do Estado de São Paulo. Bolm Inst.oceanogr., S Paulo, 32(2): 145-152.

PAIVA FILHO, A.M. 1982. Estudo sobre a ictiofauna do Canal dos Barreiros, Estuário de São Vicente, SP. Tese de livre- docência. Universidade de São Paulo, Instituto Oceanografico. 189p.

; GIANNINI, R.; RIBEIRO NETO, F.B. \& SCHMIEGELOW, J.M.M. 1987. Ictiofauna do complexo baía-estuário de Santos e São Vicente, SP, Brasil. Relat. int. Inst. oceanogr. Univ. S Paulo, (17): 1-10.

\& SCHMIEGELOW, J.M.M. 1986. Estudo sobre a ictiofauna acompanhante da pesca do camarāo sete-barbas, Xyphopenaeus kroyeri, nas proximidades da Baía de Santos, SP. Bolm Inst.oceanogr., S Paulo, 34 (único): 79-85.
PAIVA FILHO, A.M. \& TOSCANO, A.P. 1987. Estudo comparativo ę variação da ictiofauna na zona entre-marés do Mar Casado-Guarujá e Mar Pequeno-Sāo Vicente, SP. Bolm Inst. oceanogr., S Paulo, 35 (2): 153-165.

PEREIRA, N. 1985. Eutrofização no sistema estuarino e das baías de Santos e São Vicente (Estado de São Paulo). Dissertação de mestrado. Universidade de São Paulo, Faculdade de Saúde Pública. 2v.

PLA, L.E. 1986. Analisis multivariado: metodo de componentes principales. Sér. Mat. O.E.A., (27):90p.

RIBEIRO NETO, F. B. 1989. Estudo da comunidade de peixes da Baía de Santos, SP. Dissertação de mestrado. Universidade de Sāo Paulo. Instituto Oceanográfico. 196p.

SINQUE, C. 1977. Distribuição do ictioplâncton na região lagunar de Cananéia e descrição das larvas da família Sciaenidae (Teleostei). Tese de doutorado. Universidade de Sāo Paulo, Instituto de Biociências. $127 \mathrm{p}$.

SOARES, L.S.H. 1983. Aspectos da biologia e ecologia de Isopisthus parvipinnis (Cuvier, 1830) (Perciformes: Sciaenidae) entre Cabo Frio e Torres, Brasil. Dissertação de mestrado. Universidade de São Paulo, Instituto Oceanográfico. 123p.

SONDOTÉCNICA ENGENHARIA DE SOLOS S.A. 1977. Comportamento hidráulico e sedimentológico do estuário santista (relatório final). M.T., Portobrás, I.N.P.H. 180 p.

SOUSA, E.C.P.M. de 1979. Produção primária bentônica da zona entre marés em praias da Baixada Santista. Dissertação de mestrado. Universidade de São Paulo, Instituto Oceanográfico. 168p.

TOMMASI, L.R. 1979. Consideraçōes ecológicas sobre o sistema estuarino de Santos (SP). Tese de livre-docência. Universidade de São Paulo, Instituto . Oceanográfico. 2v.

VARGAS, C.P. 1976. Estudo sobre diferenciação geográfica de Paralonchurus brasiliensis (Steidachner, 1875) entre as latitudes $23^{\circ} 30^{\prime}$ S (Ubatuba) e $33^{\circ} \mathrm{S}$ (Albardão). Dissertaçāo de mestrado. Universidade de São Paulo, Instituto Oceanográfico. $2 v$.

VAZZOLER, A.E.A. de M. 1969. Ictiofauna da baía de Santos. I. Sciaenidae (Percoidea, Percomorphi). Bolm Inst.oceanogr., S Paulo, 18 (1):11-26. 
VAZZOLER, A.E.A. de M. 1971. Diversificação fisiológica e morfológica de Micropogonias fumien (Desmarest, 1822) ao sul de Cabo Frio, Brasil. Bolm inst. oceanogr., S Paulo, 20(2): 1-70.

VAZZOLER, G. 1975. Distribuição da fauna de peixes demersais e ecologia dos Sciaenidae da plataforma continental brasileira, entre as latitudes $29^{\circ} 21^{\prime} \mathrm{S}$ (Torres) e $33^{\circ} 44^{\prime}$ S (Chuí). Bolm Inst.oceanogr., S Paulo, 24(único): 85-169.
ZANI-TEIXEIRA, M. de L. 1983. Contribuição ao conhecimento da ictiofauna da baía do Trapandé, complexo estuarino lagunar de Cananéia, SP. Dissertaçāo de mestrado. Universidade de São Paulo, Instituto ()ceanográfico. 82p.

(Recebido em 08-06-89; aceito em 27-09-90) 